\title{
Relationships between Vehicle Pricing and Features: Data Driven Analysis of the Chinese Vehicle Market ${ }^{\dagger}$
}

\author{
Shiqi Ou ${ }^{1}\left(\right.$, Wan $\mathrm{Li}^{1}{ }^{1}, \mathrm{Jie} \mathrm{Li}^{2}$, Zhenhong Lin ${ }^{1, *}, \mathrm{Xin}^{\mathrm{H}}{ }^{3}$, Jessey Bouchard ${ }^{3}$ and \\ Steven Przesmitzki ${ }^{3}$
}

1 Energy and Transportation Science Division, Oak Ridge National Laboratory, Knoxville, TN 37932, USA; ous1@ornl.gov (S.O.); liw2@ornl.gov (W.L.)

2 China Automotive Technology and Research Center, Dongli District, Tianjin 300300, China; lijie@catarc.ac.cn

3 Aramco Services Company, Aramco Research Center-Detroit, 46535 Peary Ct, Novi, MI 48377, USA; xin.he@aramcoamericas.com (X.H.); jessey.bouchard@aramcoamericas.com (J.B.); steven.przesmitzki@aramcoamericas.com (S.P.)

* Correspondence: linz@ornl.gov

+ This manuscript has been authored by UT-Battelle, LLC under Contract No. DE-AC05-00OR22725 with the U.S. Department of Energy. The United States Government retains and the publisher, by accepting the article for publication, acknowledges that the United States Government retains a nonexclusive, paid-up, irrevocable, world-wide license to publish or reproduce the published form of this manuscript, or allow others to do so, for United States Government purposes. The Department of Energy will provide public access to these results of federally sponsored research in accordance with the DOE Public Access Plan

(http://energy.gov/downloas/doe-public-access-plan).

Received: 14 May 2020; Accepted: 9 June 2020; Published: 15 June 2020

check for updates

\begin{abstract}
A full-scale understanding of the dynamics of the Chinese vehicle market can benefit stakeholders with respect to rational decision-making and effective long-term investment. This study attempts to discover the common vehicle pricing patterns in the Chinese market by quantifying statistical correlations among critical vehicle features from intrinsic powertrain systems to extrinsic market positioning. The data samples involve almost all passenger vehicle models sold in 2013 to 2019. After comparing multiple statistical methodologies, a log-transformation variant of the multinomial linear regression model was found to be the best one, and the goodness of fit shows that this model can offer stable estimates, which were validated using 2019 market data. The insights achieved are: (1) The price and major performance features of SUVs/crossovers are similar to those of sedans; (2) If all other explicit features remain the same, the price of a Japanese midsize sedan is $62 \%$ higher than that of a Chinese midsize sedan, and European midsize vehicles have the highest prices overall. (3) The incremental price of fuel consumption varies by vehicle class and fuel economy. For example, from 30 to $50 \mathrm{MPG}$, the vehicle price increases by $\$ 119$ for a Chinese brand sedan vehicle, by $\$ 69$ for a Chinese brand SUV.
\end{abstract}

Keywords: market analysis; vehicle price; vehicle brand; fuel economy; China

\section{Introduction}

Rapid wealth accumulation in China and the enormous growth of the Chinese middle class are transforming the Chinese vehicle market [1]. According to the China Automotive Technology and Research Center (CATARC), the total motor vehicle stock in China reached 348 million by the end of 2019, and the passenger vehicle population increased to around 201 million units [2]. Though, as a developing country, China has grown to be one of the largest passenger vehicle markets in the world [3], and the market dynamics is closely watched upon by the stakeholders in the world. On one hand, the sustainability of the vehicle market seems to be temporarily frustrated by the trade 
war and the slowdown of Chinese economics during 2018 and 2019 [4]. On the other hand, because of the growing spending power of the massive middle class in China, along with the country's resilient manufacturing industry and healthy market dynamics, people still believe that, in the long term, the prosperity of the vehicle market will continue after a transitory period of adjustment [5]. CATARC researchers have projected that the auto industry will generally recover after 2020 and that the annual vehicle sales will increase significantly by 2024 after the downturn [6]. Studies also anticipate that, by 2050 , the vehicle stock in China will increase to approximately 400-700 million [7,8].

The level of vehicle ownership (the vehicle volume per one thousand people) in China is still small, compared to developed countries [9]. As shown in Figure 1, the vehicle volume per one thousand people in China was just over 150 in 2017, equivalent to the U.S. level in the 1920s [10]. Japan, a neighboring country that is similar in terms of culture and urban population density, owned more than 600 motor vehicles per thousand people by 2018. Therefore, if the economy improves and the purchasing capacity of the middle class increases steadily, vehicle motorization should quickly occur across all regions in China, not just in the prosperous coastal areas [9]. Furthermore, the Chinese vehicle market is transitioning from a market of majority first-time buyers to a market that is more diversified and more focused on aftermarket services [11]. The used vehicle market is burgeoning as well [12].

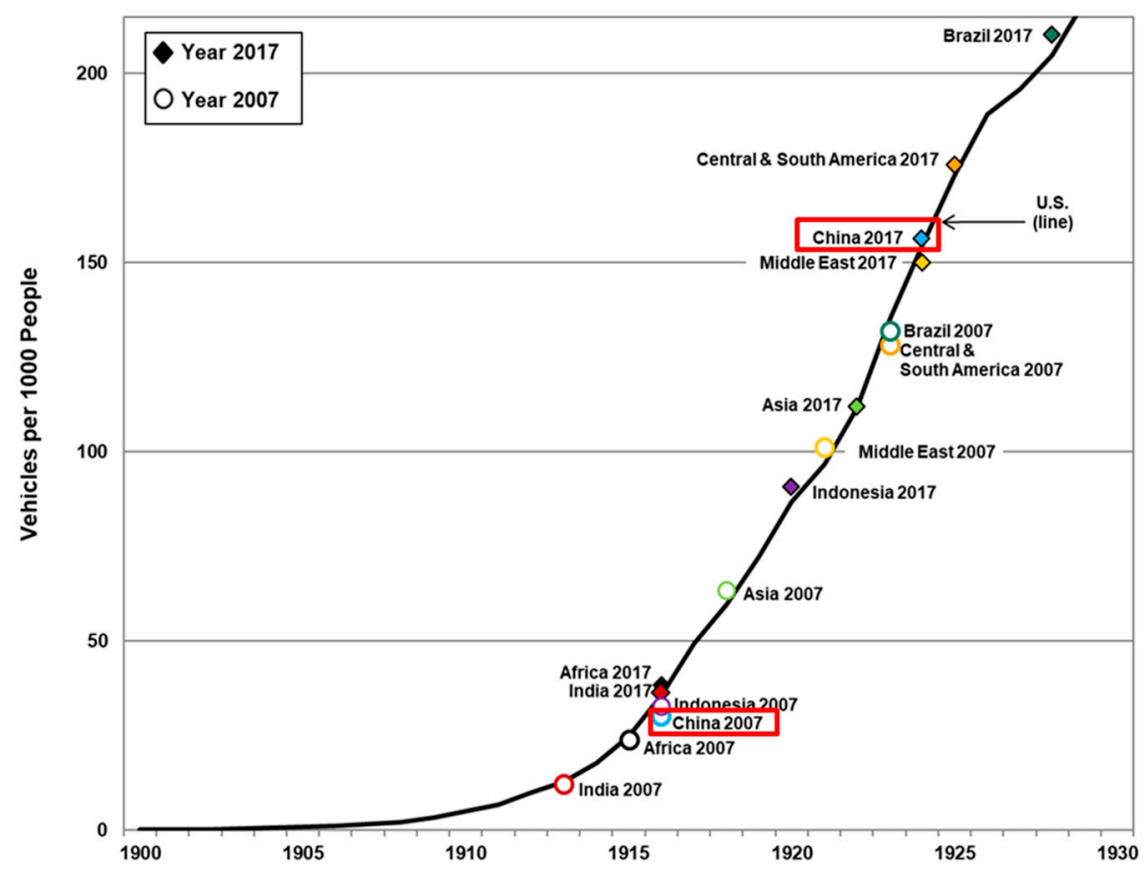

Figure 1. Vehicles per one thousand people in selected countries/regions, 2007 to 2017 (black curve shows the vehicles per 1000 people in the U.S. in 1900-1930, Reproduced/Adapted with permission from Stacy C. Davis, and Robert G. Boundy, Transportation Energy Data Book: Edition 37; published by Oak Ridge National Laboratory, 2019 (https://tedb.ornl.ogv).) [10].

In 2018-2020, the industry was experiencing an adjustment, and sales growth slowed. However, it is still regarded as a must-win market by investors, and it attracts a significant amount of capital [13]. Tesla's Shanghai factory kicked off production in the end of 2019 after just ten months of construction [14]. GM expanded its research center in China with a team of highly-qualified designers, scientists, and engineers in order to respond to consumer demands more efficiently by closely embracing local markets and manufacturing partners [15]. At the same time, the vehicle industry, viewed by the Chinese government as a strategic manufacturing industry, will be more open to foreign investors [16]. The government has announced that, by 2020, the investment restrictions regarding foreign ownership in both passenger and commercial vehicle manufacturing companies will be fully removed [17]. 
Meanwhile, the explosive growth of the vehicle market in China has inevitably raised issues related to the economy, energy security, air pollution, and urban planning [1,9]. China has been one of the worlds' largest $\mathrm{CO}_{2}$ emitters and one of the largest oil importers [18]. Road traffic accounts for about $70 \%$ of the energy consumed by the transportation sector $[18,19]$. Therefore, the Chinese government is attempting to divert the vehicle market to a more fuel-efficient and electrified pathway via government stimulus incentives, fuel economy policies, and other measures [3]. In 2017, the Chinese government released a vehicle policy, "Passenger Cars Corporate Average Fuel Consumption and New Energy Vehicle Credit Regulation," to urge the auto companies to produce highly fuel-efficient conventional vehicles or electric vehicles to achieve the stricter fuel economy standards [20].

Regardless of the specific goals of industry and the government, all of these endeavors require an understanding of the preferences of China's car buyers, especially in terms of vehicle price and features. In order to maximize profits and survive under furious market competition, auto companies need to quickly adjust their vehicle characteristics to meet consumer needs at acceptable price points. Hence, it is important for economists and market analysts to develop quantitative models or analyze market data to quickly identify emerging consumer-side market trends. Chen et al. created a mixed oligopolistic differentiated products model to investigate gaming between the supply side and the demand side, as well as gaming among different automakers [21]. This model reveals the relationships between incremental costs and technology-related vehicle characteristics, such as fuel efficiency and horsepower, by different types of automakers. Studies have shown that incremental prices by vehicle technology and by vehicle brand are important inputs in discrete choice models, which rely heavily on consumer preferences regarding various vehicle types [22,23]. Typically, the relationship between vehicle pricing and vehicle intrinsic/extrinsic features are quantified through data survey, data review, or expert assessment [24,25]. For example, the National Research Council uses data review and expert assessment to quantify the relationship between fuel economy and manufacturing cost and projects' incremental costs for further improving vehicle fuel economy by 2017, 2020, and 2025 [24]. Xie et al. conducted analyses based on a large number of regulatory and industrial documents to estimate the corresponding incremental costs associated with fuel-efficient technologies [25]. Huo et al. estimated the relationship between vehicle fuel consumption rate and vehicle weight among passenger vehicles as well as commercial vehicles [26].

Because of the strong spending power of the Chinese middle class, the more expensive premium passenger vehicle market continues to grow despite a general downturn in the vehicle market. According to Gasgoo, most premium auto brands, such as Mercedes-Benz, Audi, and BMW, experienced a growth in sales in the first half of 2019, compared to the same period in last year [27]. Car buyers have distinct purchase preferences and attitudes regarding vehicle brands, which becomes clear when examining which vehicles did not sell well in 2019. Local Chinese brands seem to be regarded as cheap, low-quality products, even though those automakers are improving their brands with attractive designs [28], sophisticated powertrain components (both fuel-powered and electrified), and innovative electronic interfaces $[29,30]$. Even if the vehicle prices are the same, profit margins can vary among car brands due to differences in the supply chain, manufacturing techniques, and cost controls. Also, Chen et al. found that, for the vehicles that are made in the joint ventures in China, the incremental costs of fuel efficiency and of alternative vehicles tend to be lower in joint ventures with Japanese firms, while the incremental costs of horsepower tend to be lower in joint ventures with U.S. firms [21]. According to our literature review, no publications have discussed the incremental price of vehicle features such as fuel efficiency or horsepower among different car brands in the Chinese vehicle market, and no studies have systematically quantified the possible relative values among the vehicle brands through data analysis.

This study applies statistical methodologies and uses historical market data to quantify the relationships between vehicle prices and features in the Chinese vehicle market in the 2010s. It has three primary objectives:

1. Estimate the price range of a vehicle based on its intrinsic/extrinsic features and performance; 
2. Identify the brand premium of vehicles (domestic product, join-venture product, and imported product);

3. Investigate the relationship between incremental vehicle prices and fuel economy (or fuel consumption rate).

By collaborating with CATARC, this study collected sales records and key powertrain information for all vehicle makes and models from 2013 to 2019 for the analyses. The following questions were addressed in this study:

- How do we quantify the relationship between vehicle price and vehicle features through big data analysis of historical data?

- Among the investigated intrinsic and extrinsic features in vehicles, which ones have the greatest impact on vehicle prices?

- For vehicles sold in China, what are the price premiums of vehicle brands from different countries/regions in recent years?

- What is the relationship between vehicle price and vehicle fuel economy (or fuel consumption rate) in the Chinese market in recent years?

This paper consists of five sections. The first section presents the motivations for and objectives of this study and discusses background literature on the passenger vehicle market and recent trends in China. The second section presents the data collection and processing efforts. The third section describes and compares the methodologies used to quantify the relationships among vehicle features. The fourth section discusses the vehicle feature analyses. The last section summarizes this study. This paper focuses only on the passenger vehicle segment, which is the dominant part of the market, so all the "vehicles" mentioned in the following context are referred to the passenger vehicles. In addition, a yearly average currency exchange rate of $\$ 1.0 \mathrm{USD}=6.620 \mathrm{CNY}$ in 2018 is used in this paper [31].

\section{Vehicle Market Data}

\subsection{Sample Analysis}

Through the data collection and processing by CATARC, this study obtains major vehicle market and vehicle performance information for the passenger vehicle models sold from 2013 to 2019 (extreme luxury sport cars were viewed as outliers and were excluded from data collection). CATARC is an independent research organization that offers consulting service on policymaking, product marketing, and consumer survey for clients from governments, auto companies, and suppliers. It owns a comprehensive database covering most aspects of the vehicle market. This study uses more than 100 million passenger vehicles (including gasoline sedans, gasoline SUVs/crossovers, and diesel SUVs/crossovers) sold in 2013-2018 for model quantification and uses vehicles sold in 2019 for model validation.

As shown in Table 1, these vehicles account for more than $98 \%$ of all passenger vehicles sold in the market in each year, except for 2013. Figure 2 summarizes both the number of models by vehicle type and the sales percentages by vehicle type from 2013 to 2018 . This study divides vehicles into two segments: sedans and SUVs/crossovers (multi-purpose vehicles are also classified as SUVs/crossovers). The gasoline sedan has been the prevalent vehicle type sold in recent years. However, the gasoline SUV/crossover is gaining popularity, and this trend is increasingly evident in the market downturn in 2018. Furthermore, 2018 is the first year SUV/crossover sales exceed sedan sales. In sum, this comprehensive, rich data improves the reliability and accuracy of the estimates in this study. 
Table 1. Data sizes (vehicle numbers) for years 2013 to 2018.

\begin{tabular}{ccccccc}
\hline Year & $\mathbf{2 0 1 3}$ & $\mathbf{2 0 1 4}$ & $\mathbf{2 0 1 5}$ & $\mathbf{2 0 1 6}$ & $\mathbf{2 0 1 7}$ & $\mathbf{2 0 1 8}$ \\
\hline Data size & $7,901,689$ & $15,000,981$ & $16,878,029$ & $19,972,388$ & $20,178,468$ & $19,251,003$ \\
\hline Percentage in actual market & $58.43 \%$ & $98.07 \%$ & $99.23 \%$ & $99.43 \%$ & $99.14 \%$ & $100.00 \%$ \\
\hline
\end{tabular}

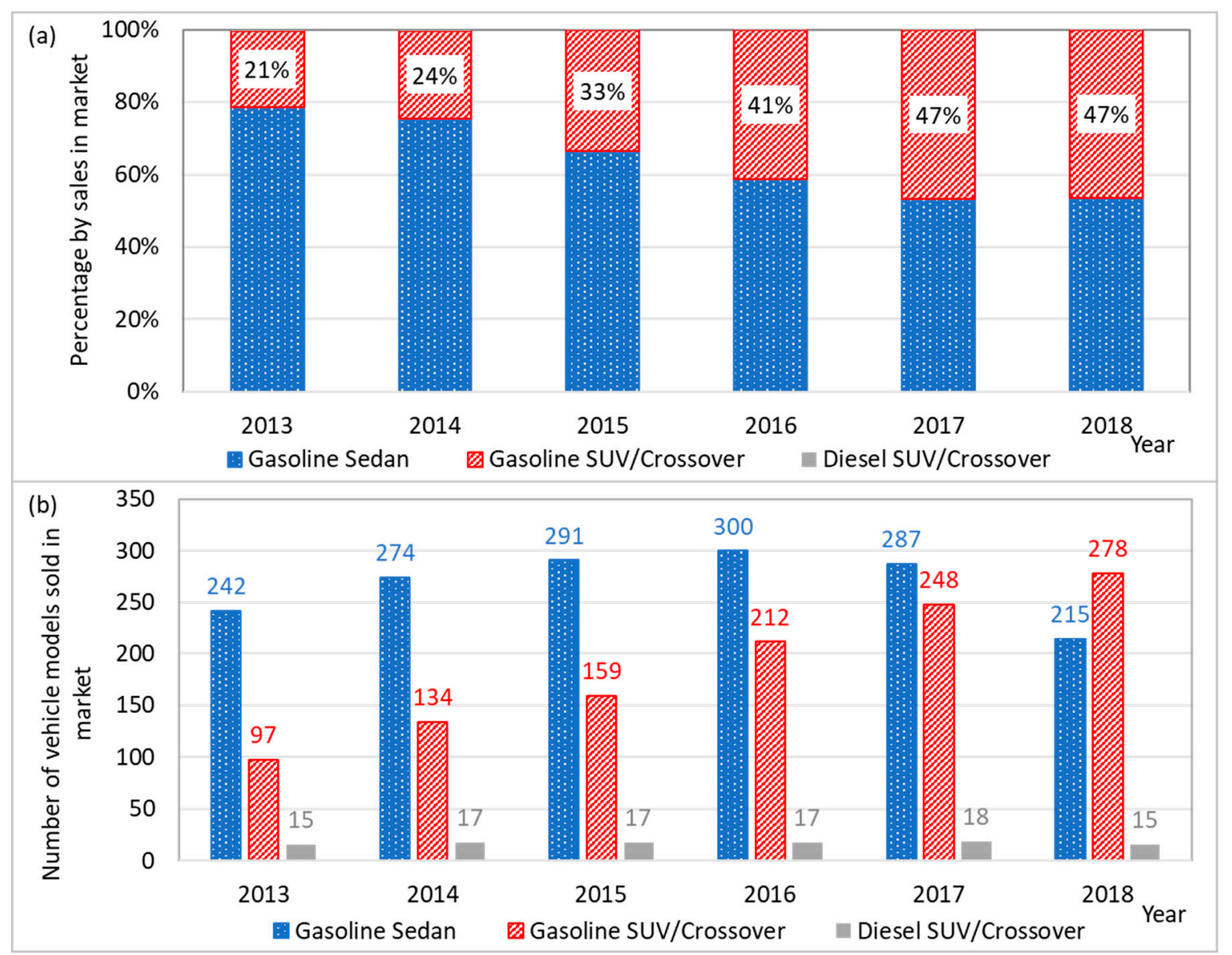

Figure 2. (a) Sales percentages by vehicle type in the Chinese market; and (b) number of vehicle models by vehicle type, 2013-2018.

The analysis of this study focuses primarily on gasoline-powered passenger vehicles, even though diesel-powered vehicles and plug-in electric vehicles (PEVs) are also sold in China. There are several reasons for this:

1. Gasoline-powered vehicles are the only products with a significant market share in the current passenger vehicle market, and this trend could continue for at least another decade in China [32].

2. The well-developed gasoline powertrain technologies and mature gasoline vehicle market ensure the robustness of the study conclusions, which are primarily based on historical market data.

3. Though PEVs are becoming popular in the Chinese vehicle market, the limited number of PEV models, the rapid changes in PEV market dynamics, and the continuous upgrades to electric vehicle technologies are very likely to discount the effectiveness of the conclusions, which are based on contemporary PEV powertrain features and historic market information.

To account for inflation, all prices are normalized to year 2018 values using the consumer price index for China as reported by the World Bank (Table 2) [33]. 
Table 2. Index for vehicle manufacturer suggested retail price (MSRP) adjustment [33].

\begin{tabular}{cccccccc}
\hline Year & $\mathbf{2 0 1 3}$ & $\mathbf{2 0 1 4}$ & $\mathbf{2 0 1 5}$ & $\mathbf{2 0 1 6}$ & $\mathbf{2 0 1 7}$ & $\mathbf{2 0 1 8}$ & $\mathbf{2 0 1 9}$ \\
\hline Price index & 91.444 & 93.201 & 94.540 & 96.431 & 97.967 & 100.000 & 102.899 \\
\hline
\end{tabular}

\subsection{Vehicle Features}

One issue this study needs to address is which explanatory variables to include in the model for quantifying the relationships among a vehicle's price and its features. It is a trade-off: if the model has too few explanatory variables, relevant variables could be missed, resulting in estimation bias (omitted variable bias); however, a model with too many variables could render an efficiency loss. In this study, the Bayesian information criterion is adopted to determine how many explanatory variables should be used in the model.

The vehicle features, which will be directly or indirectly used for the explanatory variables in the models, are segmented into three aspects: vehicle identification information, vehicle market information, and vehicle technical performance. Figure 3 shows the vehicle data structure. The vehicle identification information offers the most basic information used by buyers to differentiate between vehicles. The vehicle's model name and model year indicate its auto manufacturer and brand, which can impact buyers' purchase decisions [34]. The vehicle class includes the information on vehicle type (sedan, SUV/crossover), and the vehicle size is usually determined by curb weight, passenger/luggage volume, or other factors. Sedans are segmented into five size classes: minicompact, subcompact, compact, midsize, and large; while SUVs/crossovers are segmented into four classes: subcompact, compact, midsize, and large. The vehicle class and size were determined by CATARC, which relies heavily on the information supplied by the Ministry of Industry and Information Technology [3].

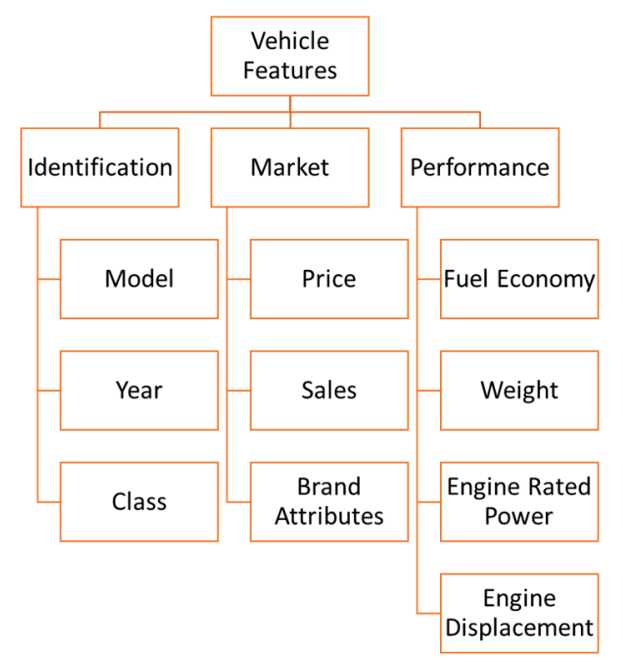

Figure 3. Schematic of major vehicle features in the analyses.

The second data category, "market," indicates the "market value" determined by consumer purchase choices. It includes the vehicle price (refer to MSRP in this article), the sales volume (used as a weighting factor), and the brand attribute (whether it is a luxury brand). CATARC classifies the following brands into the luxury (high-end) car segment: Audi, BMW, Cadillac, DS, HQ, Infiniti, Jaguar Land Rover, Lexus, Mercedes-Benz, and Volvo. This classification is based on the vehicle's target market as well as public perception. Unlike the vehicle technical specifications, which can clearly indicate the value/cost, the brand attribute is a more ambiguous concept and is hard to quantify. A superior brand may be associated with distinctive tangible and intangible benefits to vehicle buyers, even though the brand name itself never promises to offer all the services that people imagine [35]. In other words, consumers often associate a superior brand with a more stylish vehicle interior and 
design, a more comfortable or exciting driving experience, more attentive aftermarket service, or as just providing more satisfaction. Because of the intangible extra value, a favorable brand could attract buyers to pay extra money for its product even if the product quality or the aftermarket service is similar to that of other mainstream products [36]. Thus, the brand attribute is an important characteristic that could influence vehicle market price.

The vehicle "technical performance" is a critical factor that determines the essential quality of the product. Due to data limitations, this study uses four technical parameters as indicators of performance: fuel economy, vehicle weight, engine rated power, and engine displacement. The value of fuel economy informs the level of fuel-efficiency; the vehicle weight implicates vehicle size and vehicle lightweight technology, and it impacts the glider (car body without powertrain) cost in vehicle manufacturing; the size of engine rated power is related to the vehicle acceleration performance and towing capability; the size of engine displacement is related to the size of engine and the cost of aftertreatment system in the vehicle. Notably, the engine rated power and the engine displacement are commonly regarded as two different parameters-although they could correlate to each other-which should be addressed through log transformation or by increasing sample size in the model to reduce the impacts of the collinearity. Figure 4 compares the values of the major vehicle features in 2014-2019 to their 2013 values-all values are sales weighted. It shows that the fuel economy for both sedans and SUVs/crossovers increased significantly, while vehicle weight increased by much less (SUV/crossover weight stays about the same). Engine rated power increased for both vehicle types, but much more for sedans than SUVs/crossovers. As fuel economy goes up, weight and engine power go down initially (through 2016); then, they begin to increase. It would be that automakers initially improved fuel economy by reducing weight and engine power (low-hanging fruit). Then, they began improving engine/powertrain technology, which allowed them to increase vehicle weight and engine power while fuel economy continued to go up. Also, the engine displacement continues to go down, suggesting that improved technology allows them to get increased power from smaller engines. These trends indicate that the vehicles became more fuel-efficient during these years.
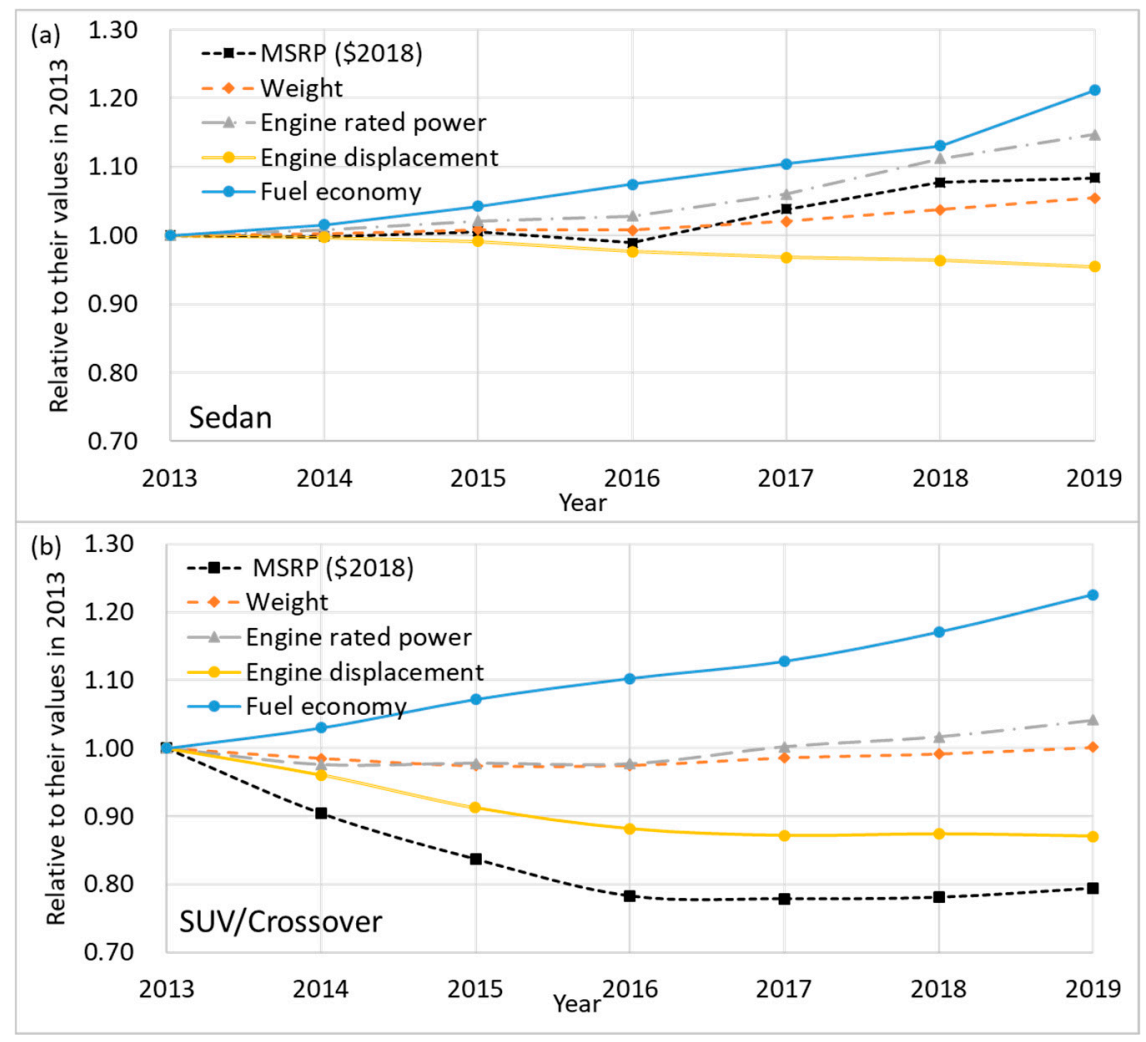

Figure 4. Relative values of major vehicle features in 2013-2019: (a) sedan and (b) SUV/crossover. 
In summary, this study collects 17 vehicle features for each vehicle model and year, including five numerical $\left(x^{1}-x^{5}\right)$ and five categorical $\left(x^{6}-x^{9}\right)$ features, as shown in Table 3. Features $x^{7}-x^{9}$ are transformed into 11 dummy variables in the vehicle price prediction model. In addition, since the range of values for different vehicle features varies widely and these conspicuous differences could affect estimating the contribution rate of the vehicle features (numerical ones), the min-max rescaling method is adopted to normalize the dataset before using these characteristics for analysis. The min-max normalization rescales the range of numerical vehicle features to fall between -1 and 1 .

Table 3. Vehicle features

\begin{tabular}{ll}
\hline$x^{1}$ & Sales, (numbers by vehicle model and year) \\
\hline$x^{2}$ & Year (e.g., 2013-2018) \\
\hline$x^{3}$ & Vehicle weight (kg) \\
\hline$x^{4}$ & Engine rated power (kW) \\
\hline$x^{5}$ & Engine displacement (Liter) \\
\hline$x^{6}$ & Fuel consumption rate (Liter/100 $\mathrm{km})$ \\
\hline$x^{7}$ & High-end brand (Higend). Dummy variable indicating whether it is a luxury brand \\
\hline$x^{8}$ & Vehicle class: minicompact (Min), subcompact (Sub), compact (Cpt), midsize (Mid), large (Lrg) for sedans; \\
\hline$x^{9}$ & Brand subcompact (Sub), compact (Cpt), midsize (Mid), large (Lrg) for SUVs/crossovers \\
\hline
\end{tabular}

\section{Methodology}

\subsection{Estimating Vehicle Prices}

The goal of vehicle price estimation is to quantify the vehicle price with correlated vehicle features summarized from the data samples. We denote aggregated features for a vehicle $\mathrm{n}$ as a vector $\widetilde{x}_{n} \in \mathbb{R}^{P}$ :

$$
\widetilde{x}_{n}=\left[\begin{array}{llll}
x_{n}^{1} & x_{n}^{2} & \ldots & x_{n}^{P}
\end{array}\right], n=1,2, \ldots N,
$$

where $N$ denotes the total number of observations (vehicle models by year), and $P$ denotes the total number of features.

The aggregate vehicle feature matrix (VFM) is shown in Equation (2), where each row represents all features of the vehicle. VFM includes all available historical data collected from the vehicle market. These data are used as the explanatory variables in the vehicle price estimation model. However, these data might not directly act as explanatory variables, because the explanatory variables, if directly used from VFM without any transformations, could cause multicollinearity in a multiple regression model process. For example, as discussed in Section 2.2, two vehicle features-vehicle weight and engine rated power-could be linearly correlated. Therefore, variants of the vehicle features are needed to avoid this issue.

$$
X_{N}^{P}=\left[\begin{array}{c}
\widetilde{x}_{1} \\
\widetilde{x}_{2} \\
\cdots \\
\tilde{x}_{N}
\end{array}\right] \in \mathbb{R}^{N \times P}
$$

The dependent variable is the vehicle price, as shown in Equation (3). The vehicle price estimation problem aims to determine a function $F(\cdot)$ that maps historical vehicle features (i.e., VFM) to their price so that, with given vehicle features, the model can roughly estimate and project the corresponding vehicle price, based on the relationships between them. 


$$
Y_{N}=\left[\begin{array}{c}
y_{1} \\
y_{2} \\
\cdots \\
y_{N}
\end{array}\right]
$$

\subsection{Methodology Comparison}

Table 4 summarizes both the pros and cons of four state-of-the-art prediction methods: partial least squares (PLS) regression, k-nearest neighbors (k-NN), support vector regression (SVR), and multinomial linear regression (MLR). There are a few characteristics that the candidate estimation/prediction methods should maintain for vehicle price estimation problems. First, this study does not only aim to provide a reliable and accurate estimation of vehicle price based on vehicle features. More importantly, it aims to answer some important research questions: What are the major factors that affect vehicle price? What is the brand implicit values of vehicles from different automakers by origin? In order to answer these questions, the estimation model should be able to generate interpretable parameters. The k-NN algorithm is a non-parametric technique for classification and regression problems. Hence, it is less preferable than the other three methods. Secondly, the proposed algorithm should generate predictions as accurately and efficiently as possible. Table 5 shows a comparison of the vehicle price prediction results among the four approaches in terms of mean absolute error (MAE) and mean absolute percentage error (MAPE). The prediction results indicate that the MLR method outperforms the PLS and k-NN methods and is comparable to SVR. Due to its easy implementation, high interpretability, and low computational complexity, this study uses MLR to estimate vehicle price.

Table 4. Pros and cons of state-of-the-art approaches.

\begin{tabular}{|c|c|c|c|c|}
\hline Method & Pros & & Cons & \\
\hline $\begin{array}{l}\text { Partial Least Squares } \\
\text { Regression }[37,38]\end{array}$ & $\begin{array}{l}1 . \\
2 . \\
3 .\end{array}$ & $\begin{array}{l}\text { Robust to noise and } \\
\text { correlated data } \\
\text { Makes few assumptions on } \\
\text { how the data are distributed } \\
\text { Can reduce the } \\
\text { data dimension }\end{array}$ & 1. & $\begin{array}{l}\text { Does not allow for the evaluation of } \\
\text { complex cause-effect relationships }\end{array}$ \\
\hline $\begin{array}{l}\text { k-nearest } \\
\text { neighbors [39] }\end{array}$ & $\begin{array}{l}1 . \\
2 . \\
3 .\end{array}$ & $\begin{array}{l}\text { Intuitive and simple } \\
\text { No assumption of } \\
\text { data distribution } \\
\text { No training steps }\end{array}$ & $\begin{array}{l}1 . \\
2 . \\
3 . \\
4 .\end{array}$ & $\begin{array}{l}\text { Curse of dimensionality } \\
\text { Needs homogeneous features } \\
\text { Does not perform well on } \\
\text { imbalanced data } \\
\text { Very sensitive to outliers }\end{array}$ \\
\hline $\begin{array}{l}\text { Support Vector } \\
\text { Regression [40] }\end{array}$ & $\begin{array}{l}1 . \\
2 .\end{array}$ & $\begin{array}{l}\text { Accurate in high } \\
\text { dimensional spaces } \\
\text { Memory efficient (only uses } \\
\text { support vectors) }\end{array}$ & $\begin{array}{l}1 . \\
2 . \\
3 .\end{array}$ & $\begin{array}{l}\text { Identification of the input space } \\
\text { dimension and kernel function can } \\
\text { be time-consuming. } \\
\text { Does not perform well for large datasets } \\
\text { Overfitting problem }\end{array}$ \\
\hline $\begin{array}{l}\text { Multinomial Linear } \\
\text { Regression [41] }\end{array}$ & $\begin{array}{l}1 . \\
2 . \\
3 .\end{array}$ & $\begin{array}{l}\text { Easy to implement } \\
\text { and understand } \\
\text { Low computational cost } \\
\text { Good interpretability }\end{array}$ & 1. & $\begin{array}{l}\text { Oversimplifies many } \\
\text { real-world problems. } \\
\text { Strong assumption, e.g., data are } \\
\text { normally distributed }\end{array}$ \\
\hline
\end{tabular}


Table 5. Comparison of model performance in terms of vehicle price estimation.

\begin{tabular}{ccc}
\hline \multirow{2}{*}{ Method } & \multicolumn{2}{c}{ Prediction Error } \\
\cline { 2 - 3 } & Mean Absolute Error & Mean Absolute Percentage Error (\%) \\
\hline PLS & 2.47 & 16.98 \\
k-NN & 2.64 & 17.46 \\
SVR & 2.12 & 16.45 \\
MLR & 2.21 & 16.58 \\
\hline
\end{tabular}

\subsection{Model Construction}

After comparing different prediction methods in Section 3.2, this study adopts the MLR method after data transformation [42] to build a statistical model and examine the potential quantitative relationships among the vehicle features, which are still unclear. Before constructing the model, all numerical vehicle features shown in Table 3 are normalized. This study fits the data for sedans and SUVs separately. The estimation model is described by Equation (4). The numerical variable $\left(x^{1}\right)$ functions as weighting factor; the four numerical variables $\left(x^{2}-x^{5}\right)$ are log-transformed based on their relationship to vehicle price [42]; and the three category variables $\left(x^{7}-x^{9}\right)$ are transformed into dummy variables. In the model, the feature indicating that vehicles belong to a Chinese brand is not assigned a dummy variable.

$$
\begin{gathered}
Y_{N}=X_{N}^{P} B+\varepsilon \\
X_{N}^{P}=\left[\begin{array}{c}
\widetilde{x}_{1} \cdot\left(x_{1}^{1}\right)^{\frac{1}{2}} \\
\tilde{x}_{2} \cdot\left(x_{2}^{1}\right)^{\frac{1}{2}} \\
\ldots \\
\tilde{x}_{N} \cdot\left(x_{N}^{1}\right)^{\frac{1}{2}}
\end{array}\right] \\
\widetilde{x}_{n}=\left[x_{n}^{2}, \ln \left(x_{n}^{3}+1\right), \ln \left(x_{n}^{4}+1\right), \ln \left(x_{n}^{5}+1\right), \ln \left(x_{n}^{6}+1\right), \overline{x_{n}^{7}}, \overline{x_{n}^{8}} \cdot x_{n}^{4}, \overline{x_{n}^{9}}\right] \\
Y_{N}=\left[\begin{array}{c}
\ln \left(y_{1}\right) \cdot\left(x_{1}^{1}\right)^{\frac{1}{2}} \\
\ln \left(y_{2}\right) \cdot\left(x_{N}^{1}\right)^{\frac{1}{2}} \\
\ldots \\
\ln \left(y_{N}\right) \cdot\left(x_{N}^{1}\right)^{\frac{1}{2}}
\end{array}\right]
\end{gathered}
$$

where $B=\left[\beta^{2}, \beta^{3}, \cdots, \beta^{P}\right]^{-1}$ contains all the coefficients calculated in this multinomial regression model; $\left[x_{1}^{1}, x_{2}^{1}, \ldots, x_{N}^{1}\right]$ represents vehicle sales by vehicle model and year in 2013-2018 and is used as the weighting factor for the samples; $Y_{n}$ contains all prices by vehicle model in 2013-2018; and $\overline{x_{n}^{7}}$, $\overline{x_{n}^{8}}$, and $\overline{x_{n}^{9}}$ includes the dummy variables. $\varepsilon=\left[e_{1}, e_{2}, \cdots, e_{N}\right]^{-1}$ is the residual. The objective is to minimize the residual value $S(b)=\varepsilon^{-1} \varepsilon=\sum_{i=1}^{N} e_{i}^{2}$. In this model, 80\% of the samples in 2013-2018 are randomly selected for training, 20\% of the samples in 2013-2018 are randomly selected for testing, and the 2019 data are used for model validation. Table 6 shows the sample sizes used in this study.

Table 6. Sample sizes (vehicle model by year) for modeling.

\begin{tabular}{lccc}
\hline & Training & Test & Validation \\
\hline Sedan segment & 2848 & 713 & 1064 \\
\hline SUV/crossover segment & 2869 & 717 & 790 \\
\hline
\end{tabular}


Table 7 shows the statistical results in the sedan segment and in the SUV/crossover segment, respectively, after fitting with the training dataset. The regression statistics indicate a good fit for both the sedan and the SUV/crossover segments, as shown in Figure 5. The adjusted R-squares are both around 0.9998 . The F-statistic values, which reveal the overall significance for the regression model, indicate that the results are highly significant in terms of variance. Furthermore, the $p$-values of the coefficients in both the sedan and the SUV/crossover segments are nearly zero, which means that the coefficients are significant as well. The overall results from the MLR model appear reliable.
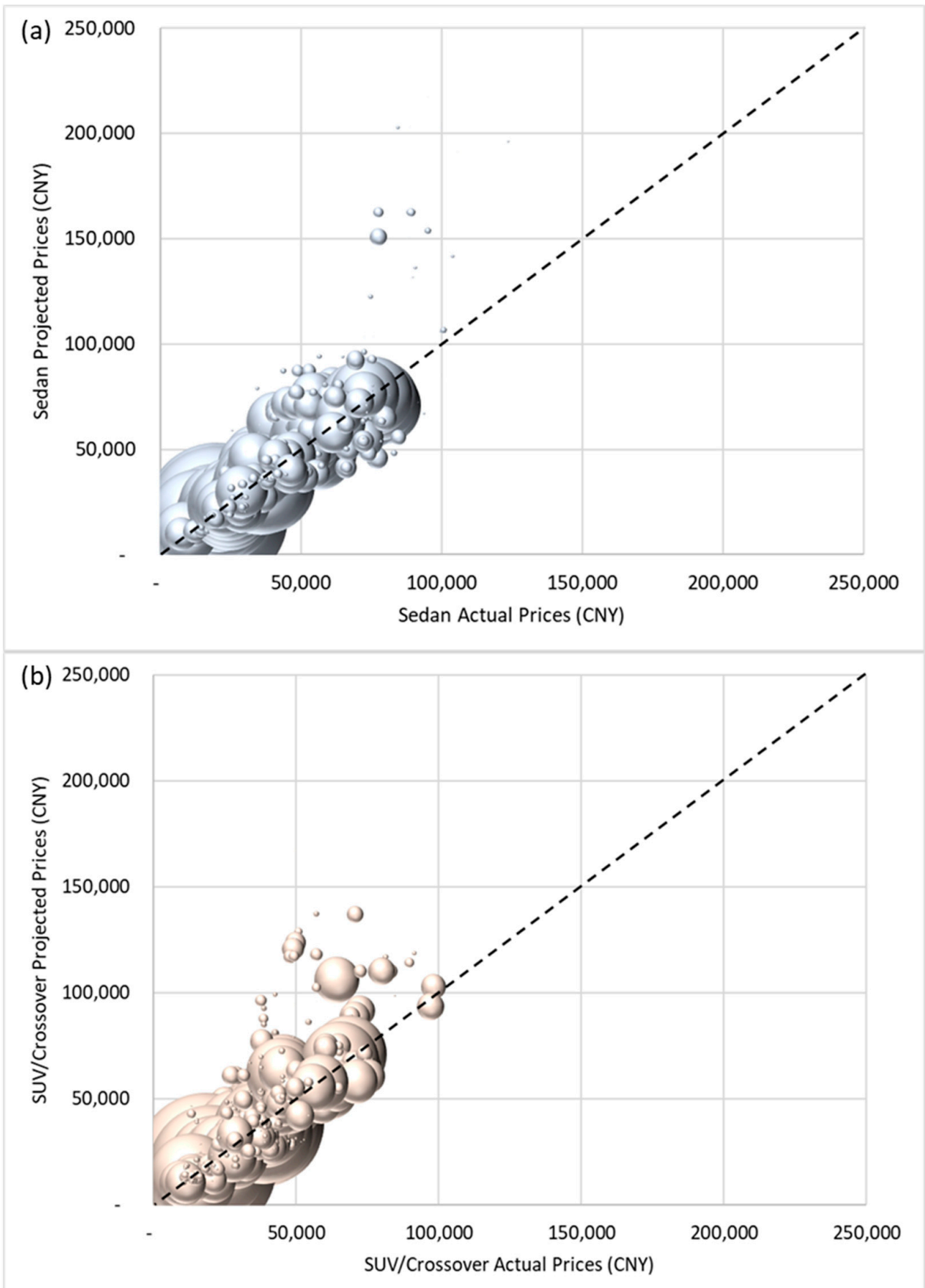

Figure 5. Comparison between actual and projected vehicle prices in the training dataset: (a) sedan; and (b) SUV/crossover. (Bubble size shows the sales of vehicle models). 
Table 7. (a) Statistical results. (b) SUV/crossover segment.

\begin{tabular}{|c|c|c|c|c|}
\hline \multicolumn{5}{|c|}{ (a) } \\
\hline \multicolumn{5}{|c|}{ Regression Statistics } \\
\hline Multiple R & 0.9999 & & Samples & $49,495,916$ \\
\hline R Square & 0.9998 & & Standard Error & 17.3133 \\
\hline Adjusted R Square & 0.9998 & & Observations & 2848 \\
\hline \multicolumn{5}{|l|}{ ANOVA } \\
\hline & $\mathrm{df}$ & SS & MS & $\mathrm{F}$ \\
\hline Regression & 14 & $4,857,779,223.3$ & $346,984,230.2$ & $1,157,571.806$ \\
\hline Residual & 2833 & $849,196.8$ & 299.7518 & \\
\hline \multirow[t]{2}{*}{ Total } & 2847 & $4,858,628,420.1$ & & \\
\hline & Coefficients & Standard Error & t Stat & $p$-value \\
\hline$x_{n}^{2}$ & -0.128 & 0.010 & -13.208 & 0.000 \\
\hline $\ln \left(x_{n}^{3}+1\right)$ & -25.733 & 0.178 & -144.584 & 0.000 \\
\hline $\ln \left(x_{n}^{4}+1\right)$ & 0.811 & 0.098 & 8.291 & 0.000 \\
\hline $\ln \left(x_{n}^{5}+1\right)$ & 0.271 & 0.073 & 3.713 & 0.000 \\
\hline $\ln \left(x_{n}^{6}+1\right)$ & -0.587 & 0.058 & -10.208 & 0.000 \\
\hline$x_{n}^{7(\text { Higend })}$ & 0.115 & 0.014 & 7.994 & 0.000 \\
\hline$x_{n}^{8(\operatorname{Min})} \cdot x_{n}^{4}$ & 29.207 & 0.093 & 314.484 & 0.000 \\
\hline$x_{n}^{8(S u b)} \cdot x_{n}^{4}$ & 30.015 & 0.105 & 285.704 & 0.000 \\
\hline$x_{n}^{8(C p t)} \cdot x_{n}^{4}$ & 30.241 & 0.117 & 259.018 & 0.000 \\
\hline$x_{n}^{8(\mathrm{Mid})} \cdot x_{n}^{4}$ & 29.901 & 0.129 & 230.929 & 0.000 \\
\hline$x_{n}^{8(\operatorname{Lrg})} \cdot x_{n}^{4}$ & 29.349 & 0.134 & 219.492 & 0.000 \\
\hline$x_{n}^{9(E U)}$ & 0.522 & 0.008 & 68.035 & 0.000 \\
\hline$x_{n}^{9(J P)}$ & 0.485 & 0.009 & 54.906 & 0.000 \\
\hline$x_{n}^{9(K R)}$ & 0.460 & 0.010 & 45.035 & 0.000 \\
\hline$x_{n}^{9(U S)}$ & 0.384 & 0.009 & 43.264 & 0.000 \\
\hline \multicolumn{5}{|c|}{ (b) } \\
\hline \multicolumn{5}{|c|}{ Regression Statistics } \\
\hline Multiple R & 0.9999 & & Samples & $30,986,732$ \\
\hline R Square & 0.9998 & & Standard Error & 15.66797237 \\
\hline Adjusted R Square & 0.9998 & & Observations & 2869 \\
\hline \multicolumn{5}{|l|}{ ANOVA } \\
\hline & $\mathrm{df}$ & SS & MS & $\mathrm{F}$ \\
\hline Regression & 13 & $31,2891,4739$ & $2,4068,5749.1$ & 980448.4916 \\
\hline Residual & 2855 & $70,0860.6976$ & 245.4853582 & \\
\hline \multirow[t]{2}{*}{ Total } & 2868 & $31,2961,5599$ & & \\
\hline & Coefficients & Standard Error & t Stat & $p$-value \\
\hline$x_{n}^{2}$ & -0.182 & 0.012 & -14.723 & 0.000 \\
\hline $\ln \left(x_{n}^{3}+1\right)$ & -20.970 & 0.126 & -166.351 & 0.000 \\
\hline $\ln \left(x_{n}^{4}+1\right)$ & 1.765 & 0.098 & 18.052 & 0.000 \\
\hline $\ln \left(x_{n}^{5}+1\right)$ & -0.247 & 0.080 & -3.089 & 0.002 \\
\hline $\ln \left(x_{n}^{6}+1\right)$ & -0.274 & 0.073 & -3.764 & 0.000 \\
\hline$x_{n}^{7(\text { Higend })}$ & 0.294 & 0.015 & 19.089 & 0.000 \\
\hline$x_{n}^{8(S u b)} \cdot x_{n}^{4}$ & 26.944 & 0.049 & 553.989 & 0.000 \\
\hline$x_{n}^{8(C p t)} \cdot x_{n}^{4}$ & 27.250 & 0.059 & 461.653 & 0.000 \\
\hline$x_{n}^{8(\mathrm{Mid})} \cdot x_{n}^{4}$ & 26.781 & 0.067 & 398.002 & 0.000 \\
\hline$x_{n}^{8(\operatorname{Lrg})} \cdot x_{n}^{4}$ & 26.642 & 0.084 & 316.610 & 0.000 \\
\hline$x_{n}^{9(E U)}$ & 0.601 & 0.011 & 55.312 & 0.000 \\
\hline$x_{n}^{9(J P)}$ & 0.523 & 0.011 & 49.602 & 0.000 \\
\hline$x_{n}^{9(K R)}$ & 0.467 & 0.013 & 35.954 & 0.000 \\
\hline$x_{n}^{9(U S)}$ & 0.436 & 0.011 & 38.600 & 0.000 \\
\hline
\end{tabular}


In addition, Figure 6 shows the distributions of the percentage errors in the sedan test dataset and the SUV/crossover test dataset. Overall, the percentage errors of most vehicles in the sedan segment are between $-20 \%$ and $20 \%$, and the MAPE in that segment is about $15.2 \%$. The percentage errors of most vehicles in the SUV segment are also between $-20 \%$ and $20 \%$, except for large SUVs/crossovers. Most of the percentage errors for the large SUVs/crossovers are between $-40 \%$ and $40 \%$. The MAPE for the SUV/crossover segment is about $21.9 \%$.
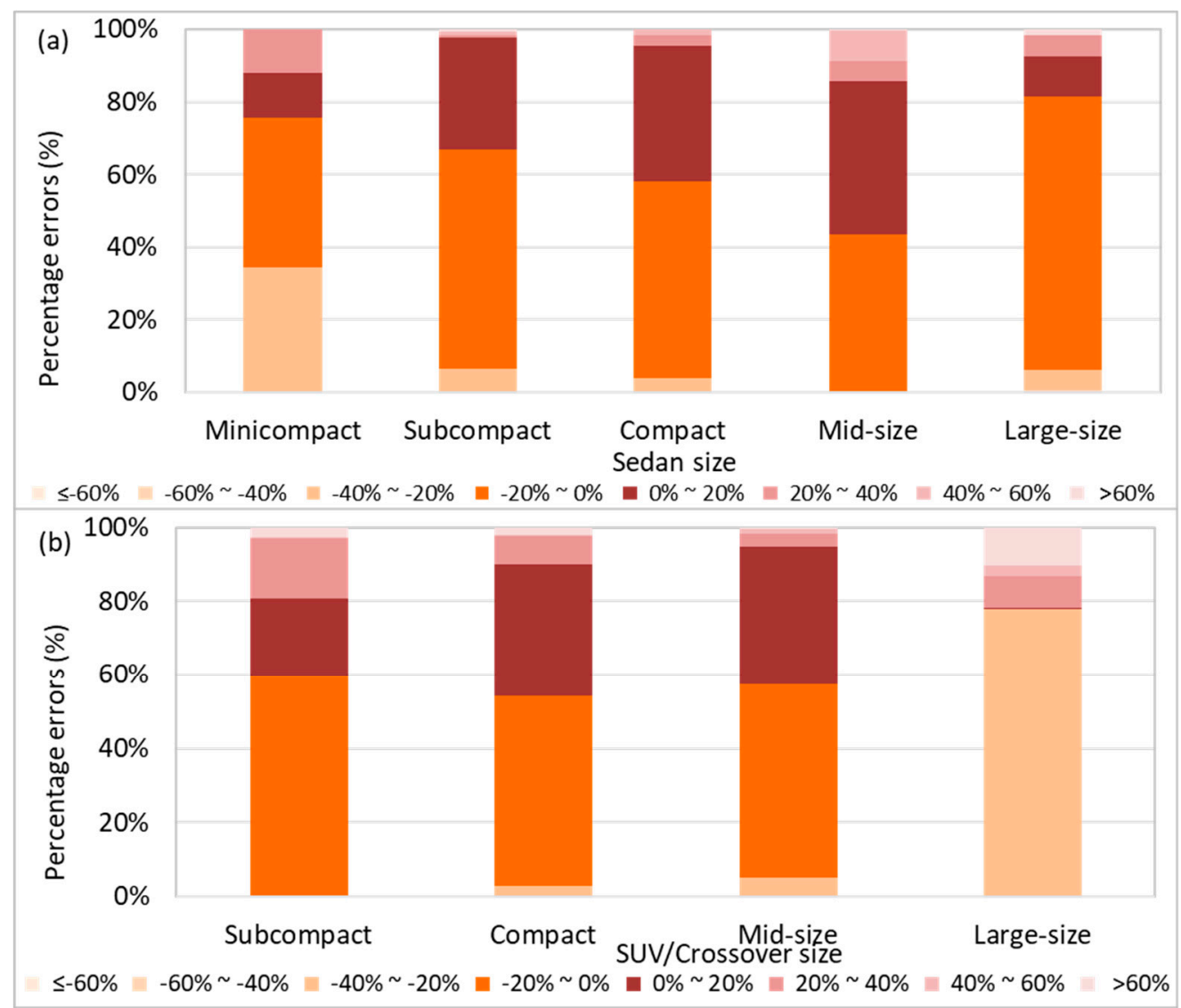

Figure 6. (a) Distributions of percentage errors in the sedan test dataset (sales-weighted) and (b) distributions of percentage errors in the SUV/crossover test dataset (sales-weighted).

\subsection{Monte Carlo Simulation}

Monte Carlo simulation is a method used for explaining the impacts of inherent uncertainty of inputs on outcomes. This study aims to visualize the potential patterns or relationships among the vehicle prices and vehicle performance and features through the market data. For each vehicle model by year, the vehicle price and its corresponding features are pre-determined. However, for a vehicle market with millions of annual vehicle sales, the aggregations of vehicle performance characteristics and features can often be described by probability density functions. The outcomes, or the vehicle prices for this type of vehicle, will be generated through the statistical model using hundreds or thousands of simulations by assigning possible input values based on their probability distributions. The outcomes are usually represented as a probability distribution, as shown in Figure 7.

Using @Risk (Version 7.0, Palisade, Ithaca, NY, USA)—a Monte Carlo simulation software tool, this study can project the distribution of the vehicle prices and the distribution of estimation errors (error means and error standard deviations) for each vehicle model in the test dataset. Figure 8 shows the estimations of both the mean values of percentage errors and standard deviations of percentage errors. 


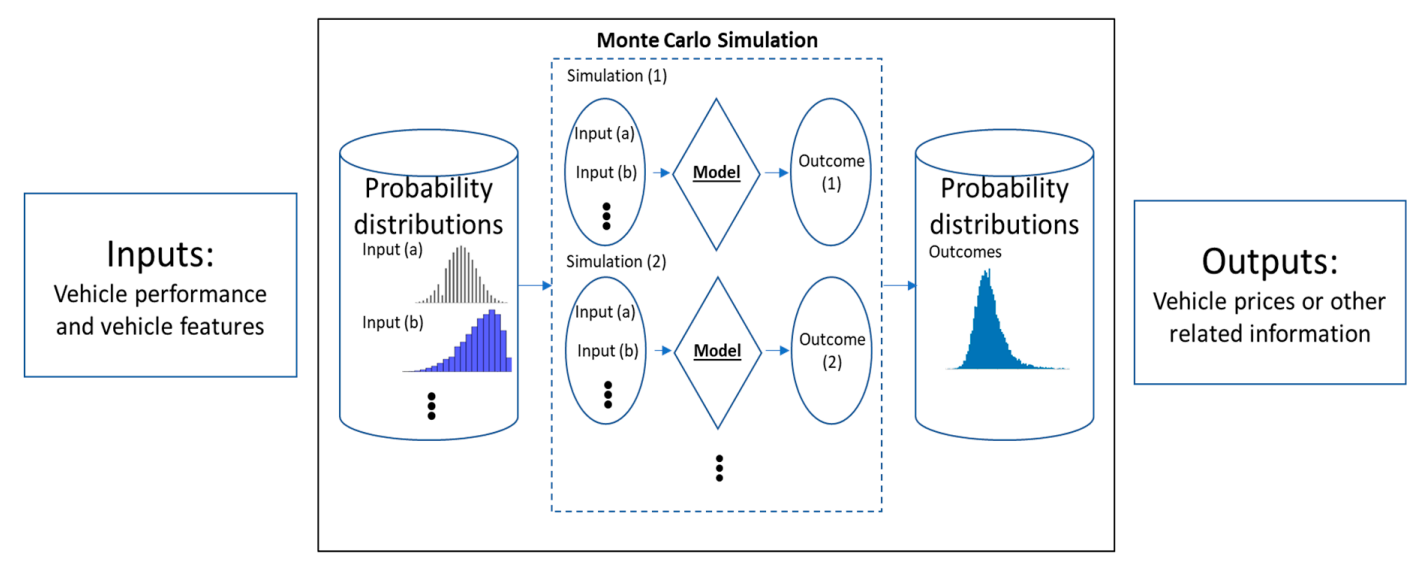

Figure 7. Flow chart of Monte Carlo Simulation.
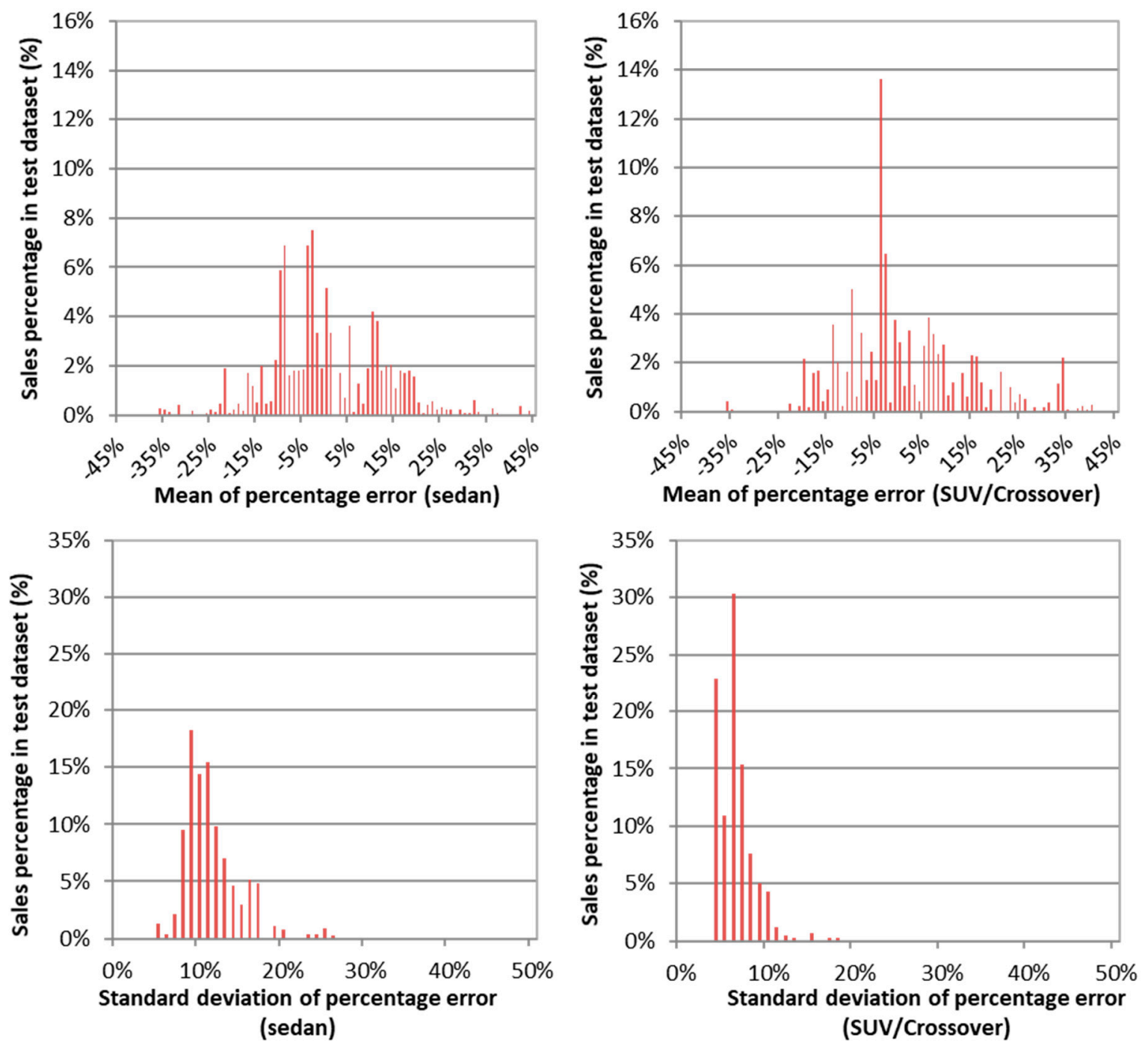

Figure 8. Means and standard deviations of percentage errors in the test datasets. 


\section{Results and Discussions}

\subsection{Data Visualization-Vehicle Fuel Economy and Vehicle Price}

Based on the data analysis and statistical modeling, this study is able to quantify the relationships between vehicle prices (normalized to 2018 U.S dollars) and vehicle features such as fuel economy (MPG), vehicle weight $(\mathrm{kg})$, and vehicle power $(\mathrm{kW})$ for the 2013-2018 Chinese vehicle market. In this section, the study summarizes the historic trends of MPG, vehicle MSRP, and relationships among vehicle powertrain features, based on the market data. The aggregate values are based on the vehicle models in the dataset only; they are not sales- or production-weighted values.

The distributions of MPG for the two vehicle segments by year and by vehicle brand are presented in Figure 9. Figure 9a shows the median MPG of the vehicle models of each segment. Overall, the MPG of both vehicle segments increases over time, and the MPG level of SUVs/crossovers increases much faster than that of sedans. Five brand origins are also compared in the study as in Figure 9b: Chinese brands (e.g., Geely and Great Wall), American brands (e.g., Ford and GM), European brands (e.g., VW and BMW), Korean brands (e.g., Hyundai and Kia), and Japanese brands (e.g., Toyota and Honda). The non-Chinese brands could be manufactured in the joint-venture factories in China or could be imported from other countries. Japanese-brand vehicles rank the highest on fuel economy in the sedan segment, but the lowest in the SUV/crossover segment, according to the 2013-2018 data. Note that the MPG values in Figure 9 are not exactly the same as the sales- or production-weighted values in other references and are, therefore, not comparable.
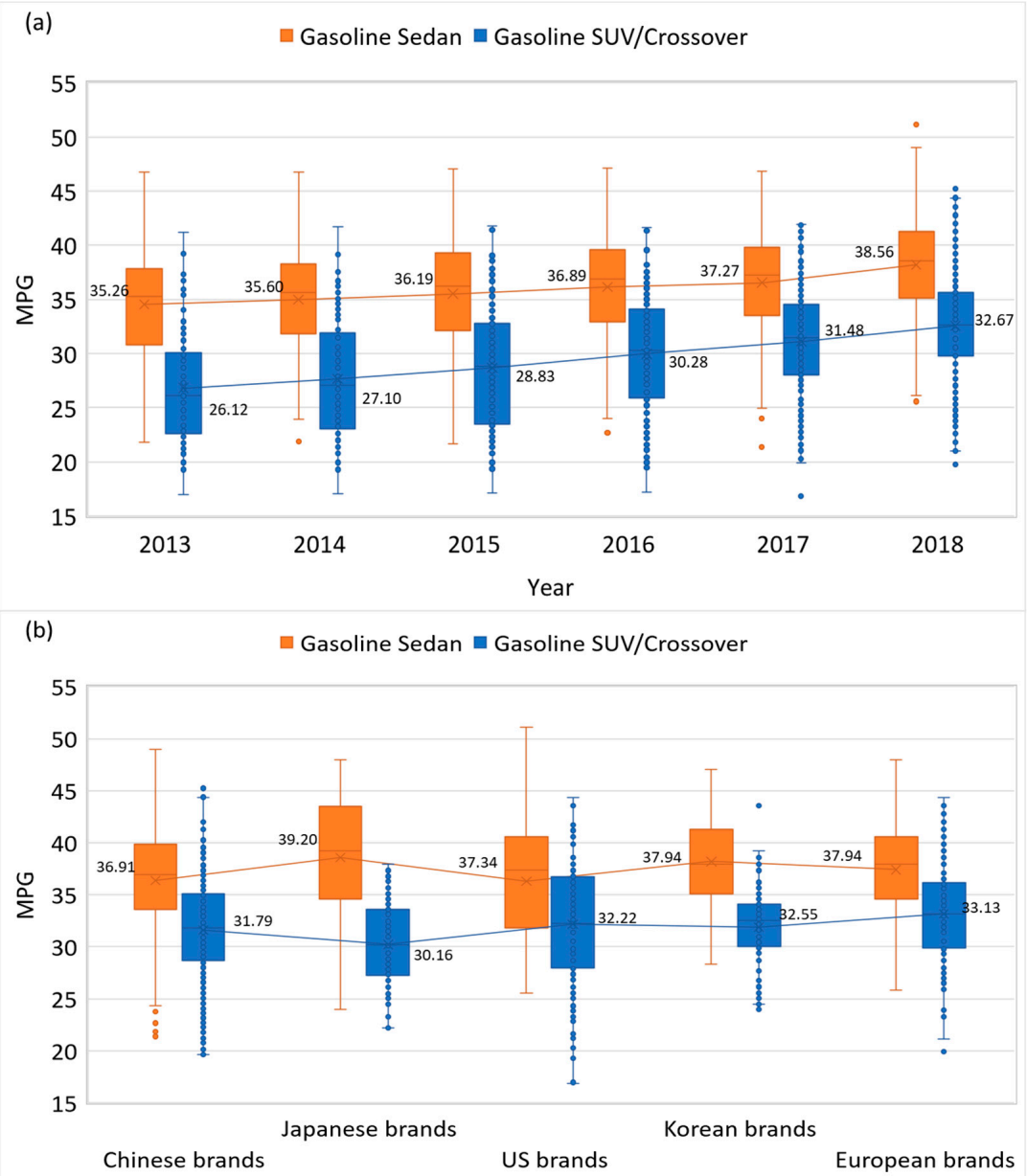

Figure 9. (a) Distributions of vehicle model Miles per Gallon (MPG) by year in 2013-2018; (b) distributions of vehicle model MPG by vehicle brand in 2013-2018. 
The distributions of MSRPs among vehicle models by year and by vehicle brand are presented in Figure 10. All vehicle prices have been converted to 2018 U.S. dollars. Figure 10a shows that the MSRP of sedan models did not change much during the study period, except for an increase in 2018. The median MSRP for 2013 was $\$ 15,175$. It decreased $\$ 600$ to $\$ 14,502$ by 2017 , but it increased to $\$ 19,909$ by 2018 . This increase in MSRP might be due to a $19.3 \%$ increase in luxury car sales in 2018 . In comparison, the MSRP of SUV/crossover models generally decreased from 2013 to 2018. In 2013, the median price of SUV/crossover models was $\$ 19,223$, and the average price was $\$ 26,948$. While in 2018 , the median price of SUV/crossover models was $\$ 18,716$, and the average price was $\$ 23,620$. One reason might be the increasingly competitive SUV/crossover market. As shown in Figure 2a, the number of SUV/crossover models in the Chinese vehicle market increased significantly from 97 in 2013 to 278 in 2018. Figure 10a shows the MSRP by vehicle brand origin. Overall, the European brands have the highest MSRP, while Chinese brands rank the lowest in overall MSRP. In addition, note that the MSRP difference between SUVs/crossovers and sedans is much larger for Japanese brands $(\$ 19,637)$ than for other brands. The median MSRP of the Japanese SUVs is $\$ 37,734$, and the median MSRP of the Japanese sedans is $\$ 18,420$.

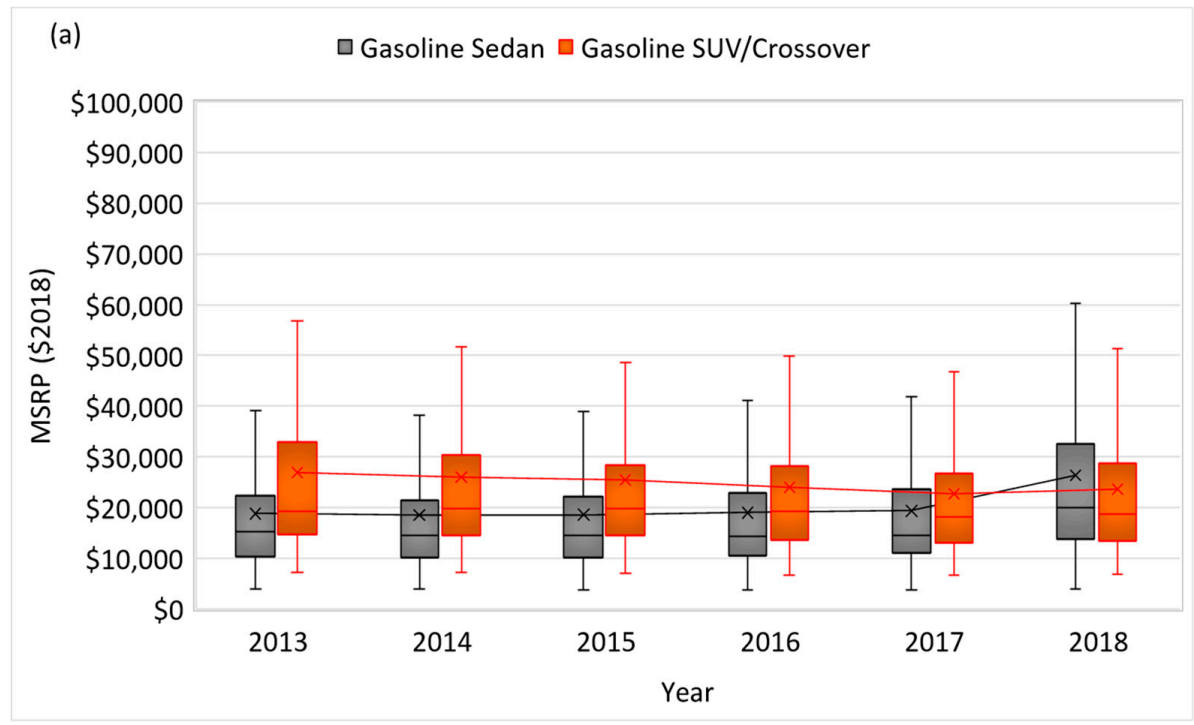

(b)

口Gasoline Sedan $\square$ Gasoline SUV/Crossover

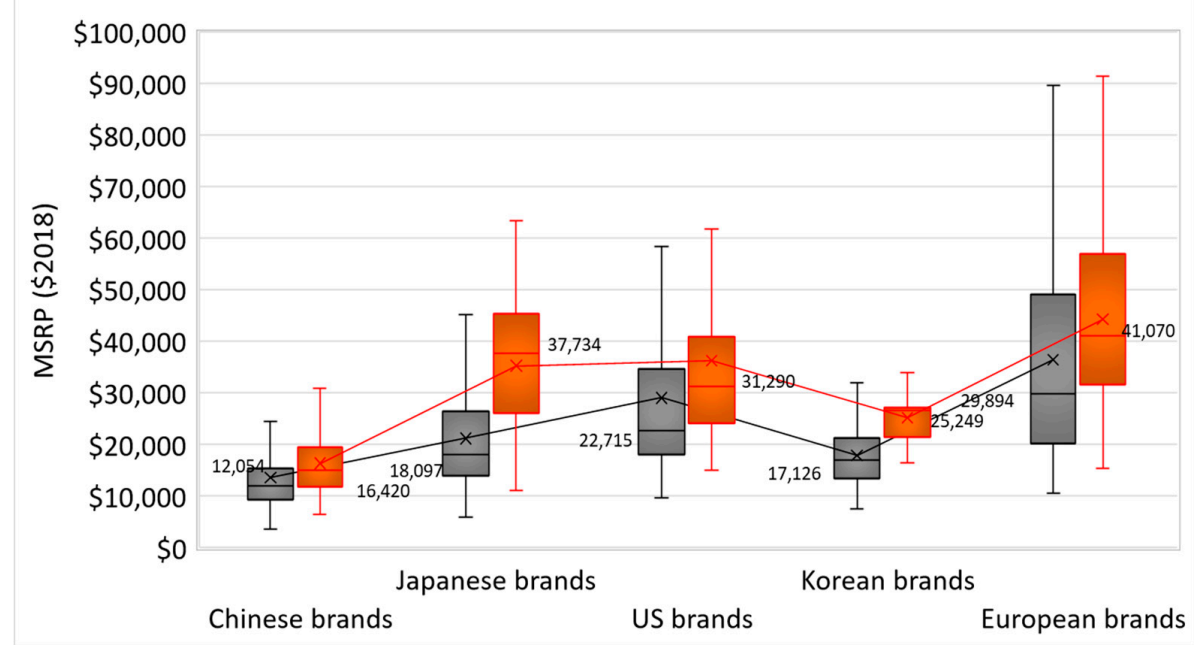

Figure 10. (a) Distributions of vehicle manufacturer's suggested retail price (MSRP) by year in 2013-2018; (b) distributions of vehicle MSRP vehicle brand in 2013-2018. 

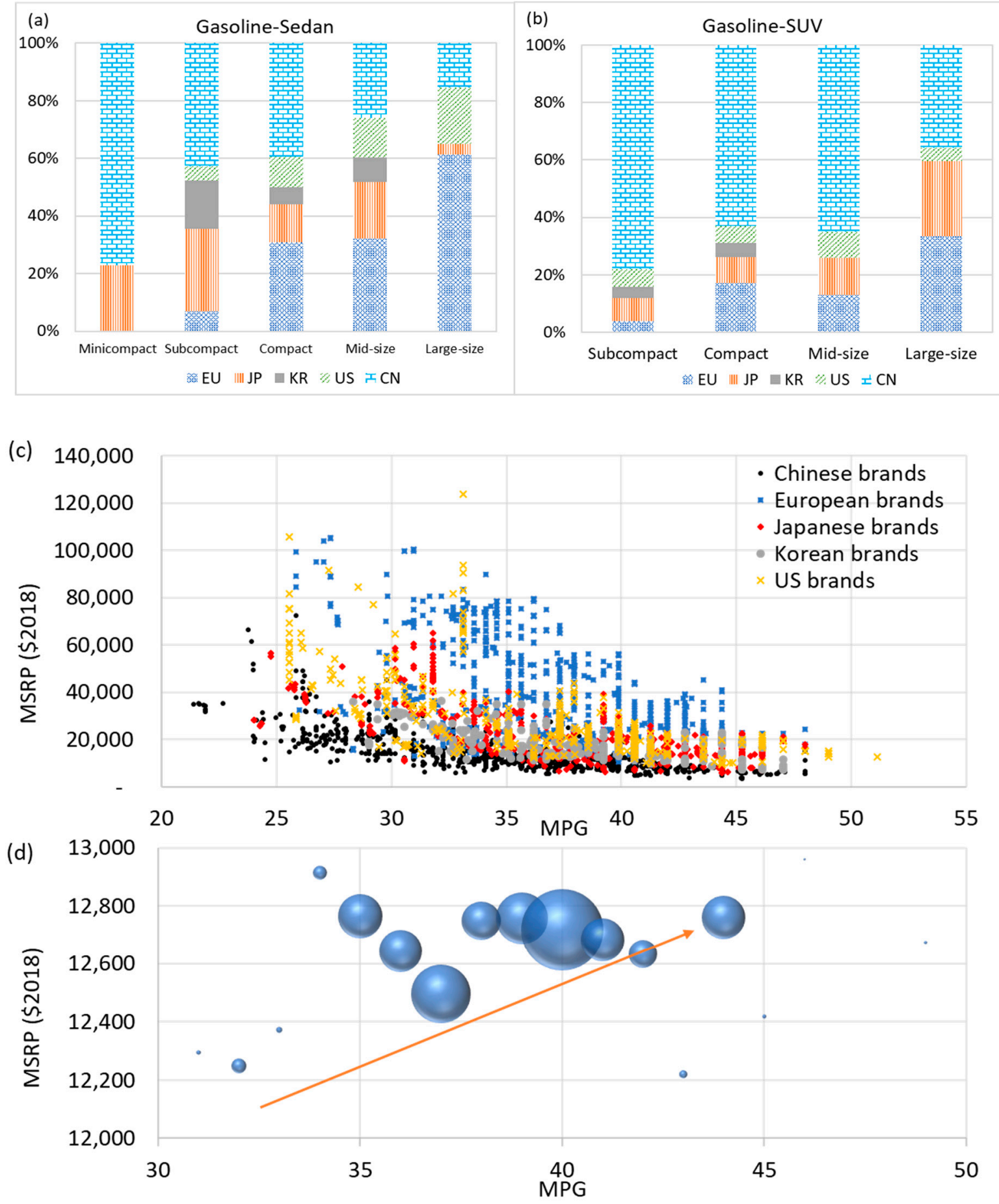

Figure 11. (a) Share of sedan models by vehicle size and by brand origin; (b) share of SUV models by vehicle size and by brand; (c) the relationship between MSRP and MPG by brand origin; and (d) relationship trend of MSRP and MPG in sedans ranging from $\$ 12,000$ to $\$ 13,000$ (bubble size indicates the sales).

Chinese brands targeted the smaller vehicle size segments, as shown in Figure 11a,b. These brands account for $77 \%$ of minicompact sedans and account for $78 \%$ of subcompact SUVs/crossovers. This may partially explain why both the MPG and the MSRP values of vehicles by Chinese automakers are lower than those of brands from other countries, as shown in Figure 11c. Since the European vehicles include some luxury brands, the MSRPs of some European vehicle models shown in Figure 11c are much 
higher than those of other brands. Moreover, as shown in Figure 11b, Chinese automakers focus more on the SUV/crossover segment. The rapid growth of SUV/crossover models in recent years (Figure 2) is due in large part to the substantial number of SUVs/crossovers produced by Chinese automakers. The change in emphasis from sedans to SUVs/crossovers by the Chinese automakers may be due to two factors: (1) to meet Chinese consumer demand for increased interior vehicle room [43] and (2) the higher profit margin of SUVs/crossovers relative to sedans [44].

Furthermore, as shown in Figure 11c, the level of fuel economy appears negatively correlated with the MSRP. This seems to contradict the conclusions by the National Research Council and other studies (such as Autonomie results) that the vehicle price commonly increases with a higher fuel economy level, since more sophisticated fuel economy technologies inevitably add the vehicle production cost $[24,45]$. However, the discrepancy is probably because this trend (a positive correlation between fuel economy and vehicle production cost) can be obscured by other factors when the data is complex and influencing factors are many. For example, as shown in Figure 11d, the positive correlation between the fuel economy and vehicle price is tenable for sedan MSRP ranges from $\$ 12,000$ to $\$ 13,000$, when car models have similar MSRPs. Therefore, a quantitative model, which can minimize the distractions of irrelevant vehicle market factors, is needed to accurately determine intrinsic relationships.

\subsection{Relationship Quantification between Vehicle Price and Features}

\subsubsection{Vehicle Price Estimation and Validation}

To validate the reliability of the statistical mode which quantifies the relationships between vehicle features and vehicle prices based on the vehicle market data, this study randomly selects 20 different sedan models and 12 different SUV/crossover models from the best-selling vehicle models in the 2019 Chinese vehicle market. In sedans, it selects four vehicle models from each of five vehicle size types (minicompact, subcompact, compact, midsize, and large), and in SUVs/crossovers, it selects three vehicle models from each of four size classes (subcompact, compact, midsize, large). Figure 12 shows the projected MSRPs based on the statistical model discussed in Section 3.3. The projected and actual MSRPs of most vehicle models are close to one another, and the deviations for most vehicle models fall within a reasonable range. However, the projected and actual MSRPs of some vehicle models differ significantly. This does not necessarily mean the model works inefficiently. It might be because the listed MSRPs of the vehicle models deviate from the market average. For example, as shown in Figure 12, the blue point in the SUV/crossover segment stands for a large SUV/crossover model produced by a Chinese manufacturer with a short history in the auto industry. The actual MSRP of this $\mathrm{SUV} /$ crossover is much lower than other similarly sized models with a similar powertrain configuration produced by more established automakers. This might be because this Chinese automaker wants to compete for that market using a low-price strategy: offering a comparable vehicle at a much lower price. Another reason might be that different automakers may have significantly different profit margins for some vehicles, especially higher-priced models. These profits are often used to offset lower profits, or even losses, on other vehicles in their lineup. Therefore, this statistical model can help analyze the "reasonableness" of vehicle prices by comparing them with the market average price range.

Although this study considers the price impacts of luxury brands and vehicle models produced by different automakers to some extent, it finds that the actual prices of a few models by Chinese brands tend to be far below the prices estimated by the statistical model and that the actual prices of some vehicle models by luxury (high-end) brands tend to be much higher than their estimated prices. These vehicle models, as outliers in the market, could shadow the accuracy of their price estimation by this statistical model, which greatly relies on historical data. On the other hand, it might imply that, compared with the overall market, the actual prices of these vehicle models could be very unusual: For an extremely cheap car, could its price be a potential indicator of low quality or unreliable performance? For an exceptionally expensive high-end car, could its price be based mostly on its intangible brand value or even based on nowhere? If modeling errors are culled, this statistical model 
could alert users to be cautious of the quality/service of a vehicle model with an abnormally low price and to be vigilant regarding a luxury vehicle with a price much higher than its estimated price.

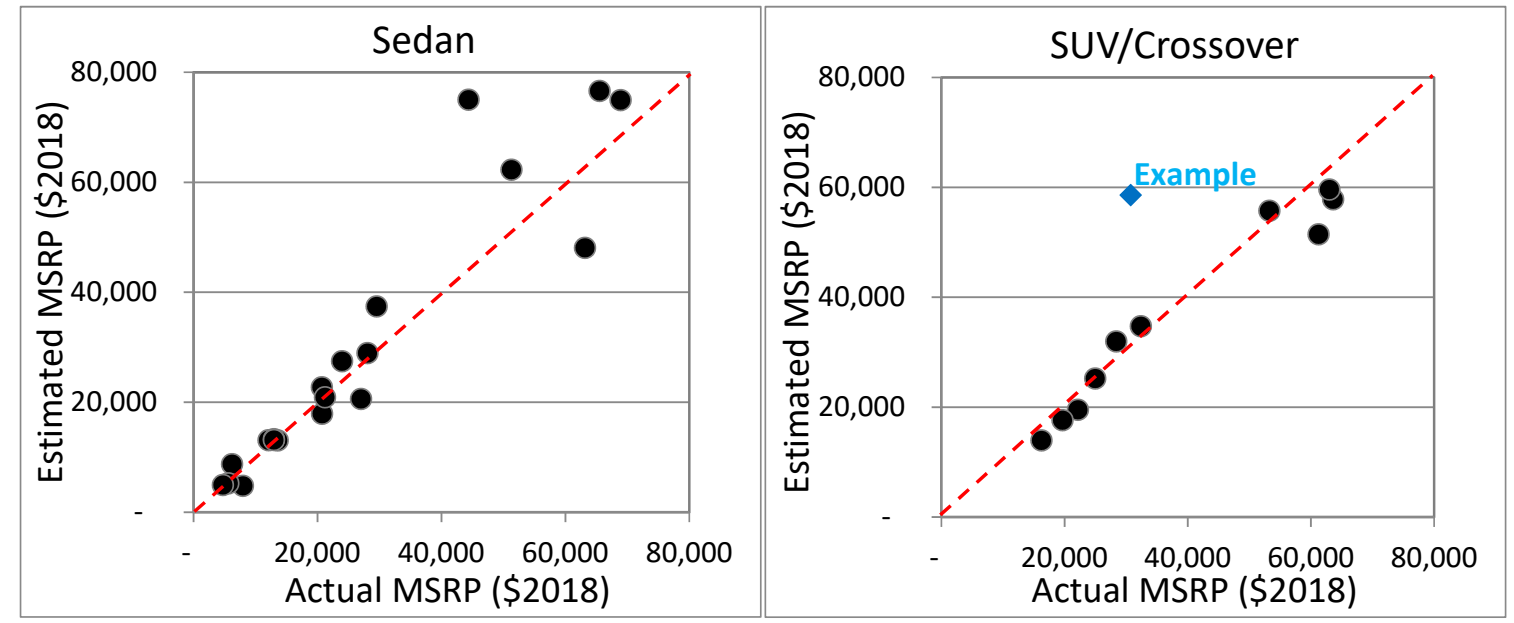

Figure 12. The out-of-sample estimates for selected vehicle models in the 2019 Chinese vehicle market.

\subsubsection{Vehicle Price Comparison among Brands}

Based on the data analyses and statistical modeling results, the average prices of vehicle segments (sedans and SUVs/crossovers) of different brands can be quantified. If all parameters other than brand origin remain the same, the impact of vehicle brand on MSRP can be determined. The difference in MSRP of Chinese brands compared to other brand origins are shown in Figure 13. The percentages and the confidence intervals (boxes) in Figure 13 signify the vehicle price change ratios compared to a Chinese brand vehicle. For example, the statistical model estimates that the MSRP for a European brand SUV/crossover could possibly be $82 \%$ higher than the MSRP of a Chinese brand SUV/crossover with the same parameter values. Furthermore, it is $90 \%$ possible that this increase in MSRP would range from $79 \%$ to $86 \%$.
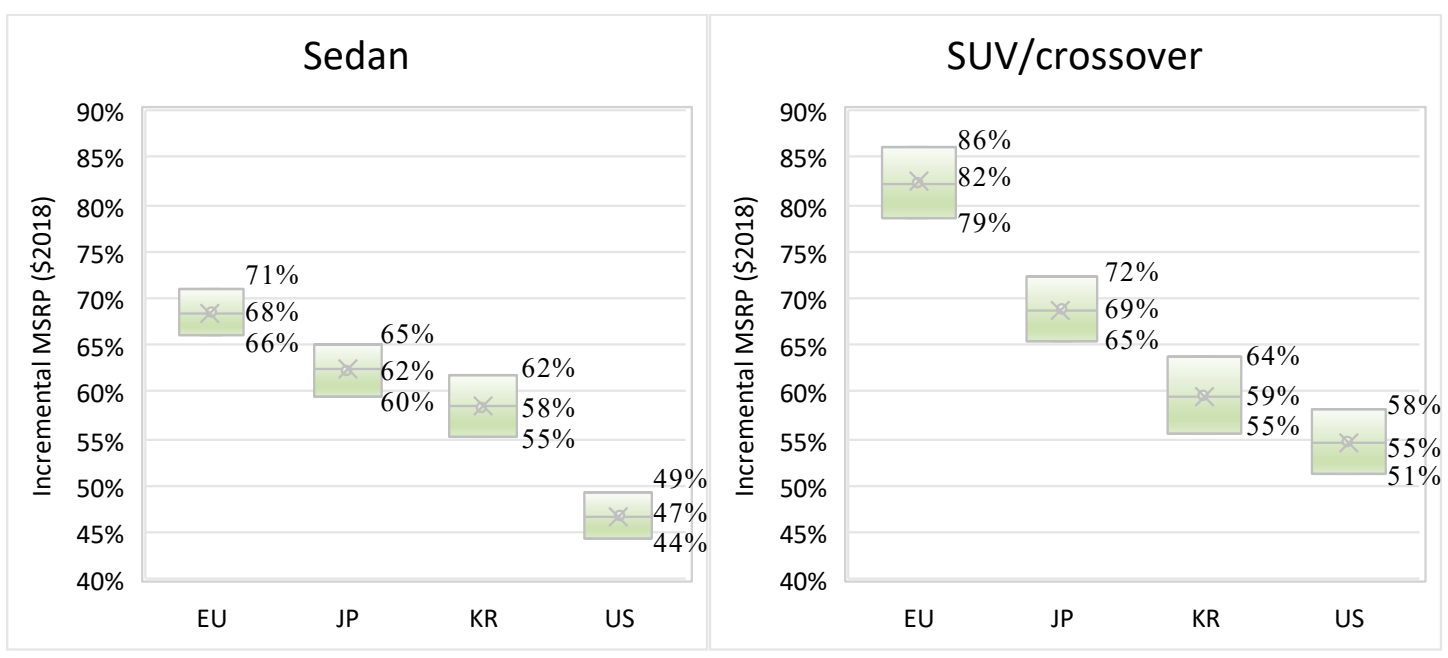

Figure 13. The relative impact of brand on vehicle MSRP, relative to the vehicles in Chinese brands.

Compared to the MSRP of a Chinese brand vehicle, the relative MSRPs of brands from Europe, Japan, Korea, and America show a remarkable increase. The MSRP difference is even greater in the SUV/crossover segment than it is in the sedan segment. The MSRP difference by brand reveals the value added for different vehicle brands. The results clearly show that, in the current vehicle market, 
the European brand vehicles have much higher added value due to brand and Chinese brand vehicles have the lowest added value due to brand. The difference in added value due to brand may come from brand premium values that are not explicitly included in the statistical model, such as high-grade interior design, more comfortable driving control (better suspension and safety performance), reliable vehicle aftermarket service, favorable public image of the brand, and other factors.

\subsubsection{Vehicle Fuel Economy and Engine Rated Power}

The effects of fuel economy (MPG) and engine rated power on vehicle MSRP are also quantified by the statistical model. Figure 14a presents the vehicle MSRP and its corresponding probability distribution for projected MSRP at different vehicle fuel economies for a midsize Chinese brand sedan. In this example, all other parameters are the sales-weighted average values for midsize sedans in the 2019 Chinese vehicle market. Based on CATARC data, the sales-weighted parameters for midsize sedans in the 2019 market are obtained: $133 \mathrm{~kW}$ for the engine rated power, $1.83 \mathrm{~L}$ for the engine displacement, and $1550 \mathrm{~kg}$ for the vehicle weight. As shown by Figure 14a, when the fuel economy increases from 20 MPG to 50 MPG, the mean value of the vehicle MSRP also increases from around $\$ 16,156$ to around $\$ 24,871$. One would expect the vehicle MSRP of a midsize sedan by other brands would be higher than the MSRPs given in Figure 14a.
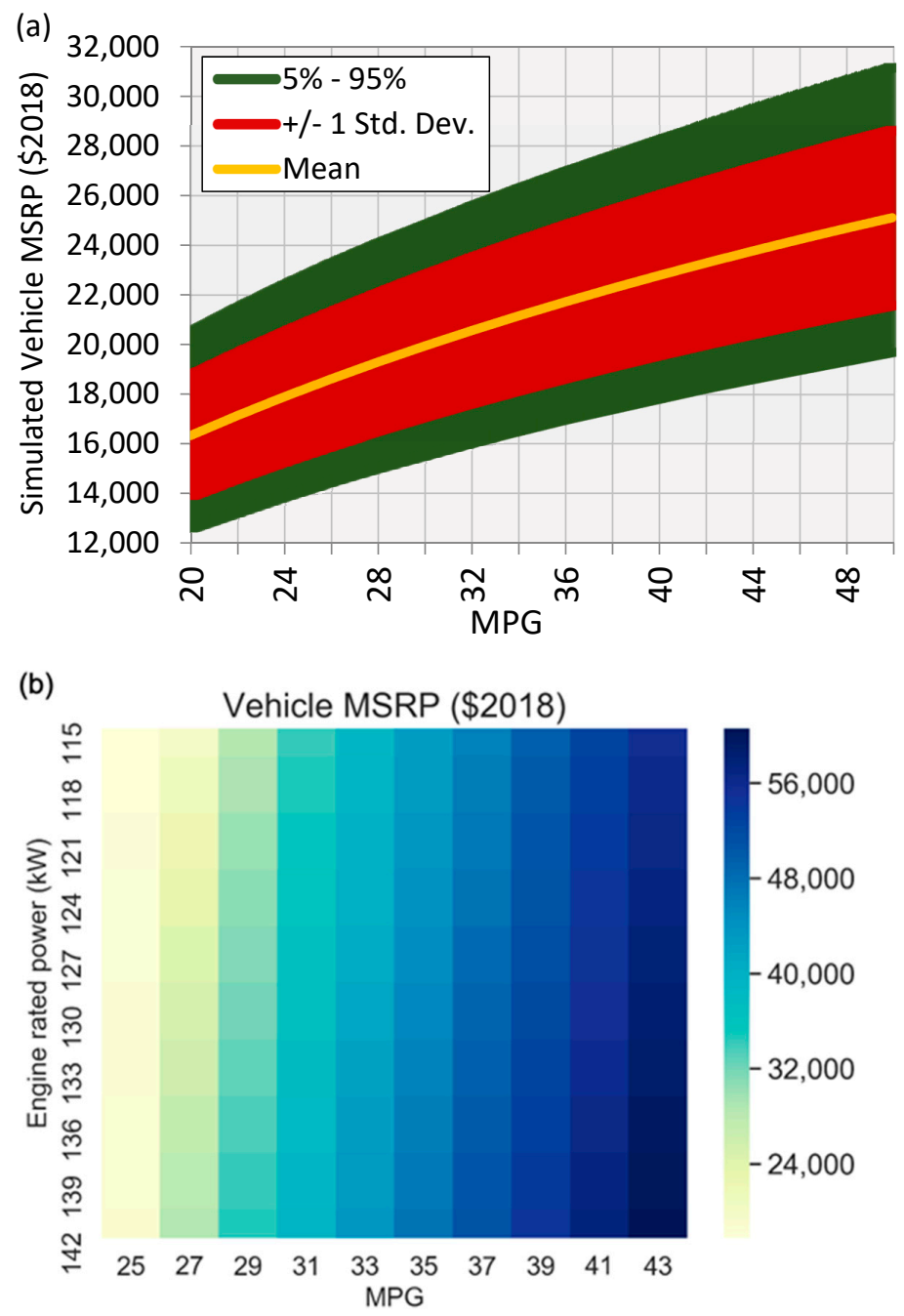

Figure 14. (a) The relationship between MSRP and fuel economy for a Chinese brand midsize vehicle; and (b) the effect of fuel economy and engine rated power on MSRP for a Chinese brand midsize vehicle. 
Figure 14b shows the effect of fuel economy and engine rated power on MSRP of a midsize Chinese brand vehicle. In the simulation, the parameters other than the fuel economy and engine rate power are the sales-weighted average values for the midsize sedans in the 2019 Chinese vehicle market. The engine rated power and vehicle fuel economy are two parameters that mutually restrain each other. Therefore, the vehicle MSRP could be extremely high when a vehicle has both a powerful engine and high fuel economy, as it would require exceptionable manufacturing technology to achieve these two performance targets.

Similarly, this study determined the incremental vehicle prices per fuel economy increase for different vehicle sales years and vehicle brand origins, which can, indirectly, be used for implicating or comparing the willingness of Chinese consumers to pay for vehicle fuel economy [46]. For a vehicle fuel economy ranging from 30 to $50 \mathrm{MPG}$, the incremental vehicle prices by vehicle sales year and brand origin are presented in Table 8. In 2013-2019, the incremental vehicle price is calculated to be $\$ 200$ to $\$ 250$ per MPG for sedans and $\$ 80$ to $\$ 130$ per MPG for SUVs/crossovers. However, the vehicle price per MPG and per weight (\$/MPG-kg) does not change much during these years. Although the vehicles become more fuel-efficient (i.e., fuel economy increases along with rated power/vehicle weight, as shown in Figure 4), the incremental vehicle price per MPG-engine-rated-power ranges from $\$ 2.1$ to $\$ 2.2$ per MPG-kW for sedans and from $\$ 0.8$ to $\$ 1.1$ per MPG-kW for SUVs/crossovers. Generally, the price per MPG-engine-rated-power did not change significantly during 2013-2019. Among the vehicle brand origins, the incremental vehicle price per MPG is correlated to MSRP: the European brands have the highest incremental vehicle price, and the Chinese brands have the lowest. In addition, in 2013-2019, the incremental vehicle price slightly increased for sedans, and it significantly decreased for SUVs/crossovers. This may be due to vehicle weight: sedans became heavier, and SUVs/crossovers became lighter. Comparably, according to Greene's estimation, the incremental vehicle price per MPG in the U.S. is around $\$ 160$ per MPG (price is not inflation adjusted) from 28 to 46 MPG in 2011 [47].

Table 8. Incremental vehicle price (MSRP) per MPG (ranging from 30 to $50 \mathrm{MPG}$ ).

\begin{tabular}{|c|c|c|c|c|c|c|c|}
\hline \multirow{2}{*}{\multicolumn{2}{|c|}{ Vehicle Feature }} & \multicolumn{3}{|c|}{ Sedan } & \multicolumn{3}{|c|}{ SUV/Crossover } \\
\hline & & Average & -S.D. * & +S.D. & Average & -S.D. & +S.D. \\
\hline \multirow{7}{*}{ Year } & 2013 & 214 & 191 & 237 & 126 & 105 & 140 \\
\hline & 2014 & 210 & 187 & 234 & 113 & 94 & 126 \\
\hline & 2015 & 212 & 188 & 237 & 102 & 85 & 114 \\
\hline & 2016 & 212 & 187 & 237 & 96 & 79 & 107 \\
\hline & 2017 & 216 & 190 & 243 & 93 & 77 & 103 \\
\hline & 2018 & 225 & 196 & 255 & 94 & 79 & 104 \\
\hline & 2019 & 235 & 204 & 269 & 99 & 84 & 110 \\
\hline \multirow{5}{*}{$\begin{array}{l}\text { Brand } \\
\text { origin }\end{array}$} & EU & 282 & 246 & 321 & 195 & 168 & 211 \\
\hline & JP & 215 & 191 & 240 & 127 & 107 & 140 \\
\hline & $\mathrm{KR}$ & 197 & 176 & 218 & 122 & 102 & 136 \\
\hline & US & 240 & 210 & 271 & 148 & 126 & 161 \\
\hline & $\mathrm{CN}$ & 119 & 109 & 130 & 69 & 57 & 78 \\
\hline
\end{tabular}

\section{Conclusions}

The goal of this paper is to quantitatively evaluate the historical vehicle market in China (2013-2019) and to determine the relationships among vehicle prices and features through statistical modeling. By collaborating with researchers from CATARC, we collect passenger vehicle sales data from 2013 to 2019, and data for more than 100 million vehicle sales are adopted for the modeling 
analyses. The market data from 2013 to 2018 are used for model training and in-sample testing, while market data from 2019 are adopted for out-of-sample estimation and validation. After comparing the stabilities and accuracies of different statistical methodologies, this study creates a linear multinomial regression model that uses dummy variables to project vehicle MSRP, based on specific vehicle features (engine rated power, engine size, fuel economy, and vehicle weight) and categories (brand origin, vehicle size class, vehicle segment [sedan or SUV/crossover], and luxury/non-luxury vehicle). The study also uses Monte Carlo simulation to quantify the possible distributions of the vehicle MSRPs by assuming vehicle feature ranges based on their historical distribution. This study may contribute valuable information to researchers and policy makers in surveying vehicle pricing and vehicle technology trends, analyzing the impacts on fuel economy and engine power in the passenger vehicle market, and evaluating the market penetration of highly fuel-efficient vehicles in China.

The results of this study offer several insights that may be of interest to stakeholders involved with the Chinese passenger vehicle and energy market:

- The SUV/crossover is the predominant vehicle type in the Chinese passenger vehicle market. The number of small SUVs/crossovers in the market is expected to increase, and their prices are decreasing until they are in line with sedan prices. The major vehicle performance features of SUVs/crossovers are nearing those of sedans.

- The fuel economy of sedan and SUV/crossover models sold in China has increased annually from 2013 to 2018. However, it has increased more rapidly for SUVs/crossovers than for sedans. Sedan fuel economy increased from 35.26 to $38.56 \mathrm{MPG}$, and SUV/crossover fuel economy increased from 26.12 to 32.67 MPG.

- Comparing the fuel economy performance among vehicle models by brand origin, on average, Japanese brands perform the best among sedans, while they perform the worst among SUVs/crossovers.

- When all other vehicle features are the same, Chinese sedans are priced lower than sedans from the other countries/regions in this study. European, Japanese, Korean, American sedans are priced $68 \%, 62 \%, 58 \%$, and $47 \%$ higher, respectively.

- When all other vehicle features are the same, the MSRP of European SUVs is $82 \%$ higher than that of Chinese SUVs/crossovers. Japanese, Korean, and American SUVs/crossovers are priced $69 \%$, $59 \%$, and $55 \%$ higher, respectively.

- In 2013-2019, the incremental MSRP per MPG is about $\$ 200$ to $\$ 250$ per MPG for sedans and about $\$ 80$ to $\$ 130$ per MPG for SUVs/crossovers.

- Vehicles became much more fuel efficient from 2013 to 2019, but incremental MSRP per MPG-engine rated power did not change much. It ranged from \$2.10 to \$2.20 per MPG-kW for sedans and from $\$ 0.80$ to $\$ 1.10$ per MPG-kW for SUVs/crossovers.

This study uses statistical modeling to perform data analyses of the Chinese passenger vehicle market. The methods and conclusions of this study can be used for vehicle ownership and consumer purchase preference analyses by others. Some assumptions are made to simplify the analysis process: only the major vehicle features are considered; only the gasoline sedan segment and the gasoline SUV/crossover segment are considered; and vehicle brands are classified according to their regional areas instead of by their brand names. As more is learned about the data and the methodology, the analysis will be updated and improved.

Author Contributions: Conceptualization, S.O.; data curation, S.O. and J.L.; formal analysis, S.O. and W.L.; funding acquisition, Z.L.; investigation, S.O. and Z.L.; methodology, S.O. and W.L.; project administration, Z.L.; supervision, Z.L.; validation, S.O. and W.L.; writing一original draft, S.O. and W.L.; writing-review and editing, S.O., Z.L., X.H., J.B., and S.P. All authors have read and agreed to the published version of the manuscript.

Funding: This research was financially supported by Aramco Services Company.

Acknowledgments: This research used resources at the National Transportation Research Center at Oak Ridge National Laboratory, a User Facility of DOE's Office Energy Efficiency and Renewable Energy. The authors 
would like to thank the data support from the China Automotive Technology and Research Center in this study. The authors would also like to thank Robert Gibson for his editing on this manuscript. The authors are solely responsible for the views expressed in this study.

Conflicts of Interest: The authors declare no conflict of interest. The funders participated in the writing and editing of the manuscript, but had no role in the design of the study; in the collection, analyses, or interpretation of data; or in the decision to publish the results.

\section{References}

1. Ou, S.; Lin, Z.; Wu, Z.; Zheng, J.; Lyu, R.; Przesmitzki, S.; He, X. A Study of China's Explosive Growth in the Plug-in Electric Vehicle Market; Oak Ridge National Laboratory: Knoxville, TN, USA, 2017.

2. CATARC. Automotive Data Center Database; China Automotive Technology and Research Center: Tianjin, China, 2018.

3. Ou, S.; Hao, X.; Lin, Z.; Wang, H.; Bouchard, J.; He, X.; Przesmitzki, S.; Wu, Z.; Zheng, J.; Lv, R.; et al. Light-duty plug-in electric vehicles in China: An overview on the market and its comparisons to the United States. Renew. Sustain. Energy Rev. 2019, 112, 747-761. [CrossRef]

4. Yang, J. Why Beijing Will Avoid Moves to Boost Slowing Economy, Weakening Car Market. Available online: https:/www.autonews.com/china-commentary/why-beijing-will-avoid-moves-boostslowing-economy-weakening-car-market (accessed on 20 November 2019).

5. Sun, Y.; Zhai, K. China's Auto Market Could Shrink About 8\% This Year: Industry Official. Available online: https://www.reuters.com/article/us-china-autos/chinas-auto-market-could-shrink-about-8-this-yearindustry-official-idUSKBN1XA0TD (accessed on 20 November 2019).

6. CATARC. Summary of China's Auto Industry in 2019 and Outlook of 2020; China Automotive Technology and Research Center: Tianjin, China, 2019.

7. Huo, H.; Wang, M. Modeling Future Vehicle Sales and Stock in China. Energy Policy 2012, 43, 17-29. [CrossRef]

8. Huo, H.; Wang, M.; Johnson, L.; He, D. Projection of Chinese Motor Vehicle Growth, Oil Demand, and $\mathrm{CO}_{2}$ Emissions Through 2050. Transp. Res. Rec. J. Transp. Res. Board 2007, 2038, 69-77. [CrossRef]

9. Wang, Y.; Teter, J.; Sperling, D. China's Soaring Vehicle Population: Even Greater Than Forecasted? Energy Policy 2011, 39, 3296-3306. [CrossRef]

10. Davis, S.C. Transportation Energy Data Book, 37th ed.; Oak Ridge National Lab., TN (US): Oak Ridge, TN, USA, 2019.

11. Liu, W.; Shen, S.; Jin, J.; Peng, B.; Fang, Y.; Xie, G.; Xiao, E.; Strom, S.; Fischer, M.; Hai, S.; et al. China Automotive Market: Witnessing the Transformation; China Automotive: Beijing, China, 2017.

12. Ang, T. Secondhand, First Choice. Available online: https://knowledge.ckgsb.edu.cn/2019/12/03/retail/usedcar-market-in-china/ (accessed on 9 April 2020).

13. Hancock, T. Why China's Auto Market Can Bounce Back. Available online: https://www.ft.com/content/ 127323ba-61a5-11e9-b285-3acd5d43599e (accessed on 20 November 2019).

14. Bloomberg. How Elon Musk Built a Tesla Factory in China in Less Than a Year. Available online: https: //fortune.com/2020/01/07/elon-musk-tesla-gigafactory-shanghai-china-ceremony/ (accessed on 12 June 2020).

15. Zhang, D. GM Looks to the Future by Investing in Technology. Available online: https://www.chinadaily. com.cn/a/201908/05/WS5d47a680a310cf3e35563ea8.html (accessed on 20 November 2019).

16. Ou, S.; Lin, Z.; He, X.; Przesmitzki, S.; Wu, Z.; Zheng, J.; Lv, R.; Qi, L. China's Booming Plug-in Electric Vehicle Market-How Will It Continue? In BT-Who's Driving Electric Cars: Understanding Consumer Adoption and Use of Plug-in Electric Cars; Contestabile, M., Tal, G., Turrentine, T., Eds.; Springer International Publishing: Cham, Switzerland, 2020; pp. 215-255, ISBN 978-3-030-38382-4.

17. Liu, W.; Peng, B.; Shen, S. The Opening-Up of Chinese Automotive Industry and its Impact; McKinsey \& Company: HongKong, China, 2018.

18. Ou, S.; Lin, Z.; Xu, G.; Hao, X.; Li, H.; Gao, Z.; He, X.; Przesmitzki, S.; Bouchard, J. The retailed gasoline price in China: Time-series analysis and future trend projection. Energy 2019, 116544. [CrossRef]

19. Chai, J.; Yang, Y.; Lu, Q.; Xing, L.; Lai, K.K.; Wang, S. Green Transportation and Energy Consumption in China, 1st ed.; Routledge Taylor \& Francis Group: New York, NY, USA, 2017; ISBN 978-1-138-03733-5.

20. Ou, S.; Lin, Z.; Qi, L.; Li, J.; He, X.; Przesmitzki, S. The dual-credit policy: Quantifying the policy impact on plug-in electric vehicle sales and industry profits in China. Energy Policy 2018, 121, 597-610. [CrossRef] 
21. Chen, Y.; Lawell, C.-Y.C.L. Supply and Demand in the Chinese Automobile Market: A Random Coefficients Mixed Oligopolistic Differentiated Products Model; Cornell University: Ithaca, NY, USA, 2019.

22. Greene, D.L.; Lin, Z.; Dong, J. Analyzing the sensitivity of hydrogen vehicle sales to consumers' preferences. Int. J. Hydrog. Energy 2013, 38, 15857-15867. [CrossRef]

23. Gnann, T.; Stephens, T.S.; Lin, Z.; Plötz, P.; Liu, C.; Brokate, J. What drives the market for plug-in electric vehicles?-A review of international PEV market diffusion models. Renew. Sustain. Energy Rev. 2018, 93, 158-164. [CrossRef]

24. National Research Council. Cost, Effectiveness, and Deployment of Fuel Economy Technologies for Light-Duty Vehicles; The National Academies Press: Washington, DC, USA, 2015; ISBN 978-0-309-37388-3.

25. Xie, F.; Lin, Z.; Nealer, R. Performance, Cost, and Market Share of Conventional Vehicle Efficiency Technologies? Retrospective Comparison of Regulatory Document Projections for Corporate Average Fuel Economy and Greenhouse Gas Standards. Transp. Res. Rec. 2017, 2628, 67-77. [CrossRef]

26. Huo, H.; He, K.; Wang, M.; Yao, Z. Vehicle technologies, fuel-economy policies, and fuel-consumption rates of Chinese vehicles. Energy Policy 2012, 43, 30-36. [CrossRef]

27. Monika Summary: Premium Auto Brands' Sales in China for July 2019. Available online: http://autonews. gasgoo.com/china_news/70016300.html (accessed on 12 January 2019).

28. Moss, T. Chinese Cars Are Still Cheap, But They're No Longer Ugly. Available online: https://www.wsj.com/ articles/chinese-cars-are-still-cheap-but-theyre-no-longer-ugly-11548417621 (accessed on 12 January 2020).

29. Shih, W. Don't Underestimate Chinese Automakers. Available online: https://www.forbes.com/sites/ willyshih/2018/07/25/dont-underestimate-chinese-auto-makers/\#3dc1116fec96 (accessed on 12 June 2020).

30. Zhou, A.; Chen, L.; Wu, Z.; Li, S.; Che, H.; Du, T.; Wang, N.; Song, P. 2018 China Domestic Auto Brand Whitepaper; Deloitte: Shanghai, China, 2018.

31. U.S. Internal Revenue Service Yearly Average Currency Exchange Rates. Available online: https://www.irs.gov/ individuals/international-taxpayers/yearly-average-currency-exchange-rates (accessed on 12 January 2017).

32. Wu, H.; Alberts, G.; Hooper, J.; Walton, B. New Market. New Entrants. New Challenges. Battery Electric Vehicles; Deloitte: London, UK, 2019.

33. The World Bank Consumer Price Index $(2010=100)$-China. Available online: https://data.worldbank.org/ indicator/FP.CPI.TOTL?end=2019\&locations $=C N \& s t a r t=1986 \&$ view $=$ chart (accessed on 13 April 2020).

34. Shirin, A.; Puth, G. Customer satisfaction, brand trust and variety seeking as determinants of brand loyalty. Afr. J. Bus. Manag. 2011, 5, 11899-11915.

35. Kamakura, W.A.; Russell, G. Measuring brand value with scanner data. Int. J. Res. Mark. 1993, 10, 9-22. [CrossRef]

36. Günther, T.; Kriegbaum-Kling, C. Brand Valuation and Control: An Empirical Study. Schmalenbach Bus. Rev. 2001, 53, 263-294. [CrossRef]

37. Abdi, H. Partial least squares regression and projection on latent structure regression (PLS Regression). Wiley Interdiscip. Rev. Comput. Stat. 2010, 2, 97-106. [CrossRef]

38. Li, W.; Wang, J.; Fan, R.; Zhang, Y.; Guo, Q.; Siddique, C.; Ban, X. (Jeff) Short-term traffic state prediction from latent structures: Accuracy vs. efficiency. Transp. Res. Part C Emerg. Technol. 2020, 111, 72-90. [CrossRef]

39. Dudani, S.A. The Distance-Weighted k-Nearest-Neighbor Rule. IEEE Trans. Syst. Man. Cybern. 1976, SMC-6, 325-327. [CrossRef]

40. Drucker, H.; Burges, C.J.C.; Kaufman, L.; Smola, A.J.; Vapnik, V. Support vector regression machines. In Advances in Neural Information Processing Systems; 1997; pp. 155-161.

41. Seber, G.A.F.; Lee, A.J. Linear Regression Analysis, 2nd ed.; John Wiley \& Sons: Hoboken, NJ, USA, 2012; Volume 329, ISBN 1118274423.

42. Ou, S.; Yu, R.; Lin, Z.; Ren, H.; He, X.; Przesmitzki, S.; Bouchard, J. Intensity and daily pattern of passenger vehicle use by region and class in China: Estimation and implications for energy use and electrification. In Mitigation and Adaptation Strategies for Global Change; 2019; pp. 1-21. [CrossRef]

43. Eloot, K.; Huang, A.; Lehnich, M. A New Era for Manufacturing in China; McKinsey \& Company: Shanghai, China, 2013; Volume 1.

44. Rogozhin, A.; Gallaher, M.; McManus, W. Automobile Industry Retail Price Equivalent and Indirect Cost Multipliers; U.S. Environmental Protection Agency: Washington, DC, USA, 2009.

45. Islam, E.; Moawad, A.; Kim, N.; Rousseau, A. An Extensive Study on Sizing, Energy Consumption, and Cost of Advanced Vehicle Technologies; Argonne National Laboratory: Argonne, IL, USA, 2018. 
46. Greene, D.L.; Evans, D.H.; Hiestand, J. Survey evidence on the willingness of U.S. consumers to pay for automotive fuel economy. Energy Policy 2013, 61, 1539-1550. [CrossRef]

47. Greene, D.L. Uncertainty, loss aversion, and markets for energy efficiency. Energy Econ. 2011, 33, 608-616. [CrossRef]

(C) 2020 by the authors. Licensee MDPI, Basel, Switzerland. This article is an open access article distributed under the terms and conditions of the Creative Commons Attribution (CC BY) license (http://creativecommons.org/licenses/by/4.0/). 